NBER WORKING PAPER SERIES

\title{
ESTIMATING THE ELASTICITY OF INTERTEMPORAL SUBSTITUTION USING MORTGAGE NOTCHES
}

\author{
Michael Carlos Best \\ James Cloyne \\ Ethan Ilzetzki \\ Henrik Kleven \\ Working Paper 24948 \\ http://www.nber.org/papers/w24948 \\ NATIONAL BUREAU OF ECONOMIC RESEARCH \\ 1050 Massachusetts Avenue \\ Cambridge, MA 02138 \\ August 2018
}

We thank the editor, Adam Szeidl, four anonymous referees, Orazio Attanasio, Adrien Auclert, Chris Carroll, Raj Chetty, Jeff Clemens, Gordon Dahl, Mariacristina De Nardi, Rebecca Diamond, Roger Gordon, Bob Hall, Ethan Kaplan, Greg Kaplan, Patrick Kehoe, David Laibson, Emi Nakamura, Petra Persson, Ricardo Reis, Jose-Victor Rios-Rull, Emmanuel Saez, Orie Shelef, Jón Steinsson, Gregory Thwaites, Gianluca Violante, Garry Young, and Stephen Zeldes for helpful comments and discussion. All charts and estimates use data provided to the Bank of England by the Financial Conduct Authority and MoneyFacts. This research was carried out as part of the Bank of England's One Bank Research Agenda and an earlier draft was circulated under the title "Interest rates, debt and intertemporal allocation: evidence from notched mortgage contracts in the United Kingdom." The views expressed are those of the authors and do not necessarily reflect the views of the Bank of England, the Monetary Policy Committee, the Financial Policy Committee, the Prudential Regulatory Authority, or the National Bureau of Economic Research.

At least one co-author has disclosed a financial relationship of potential relevance for this research. Further information is available online at http://www.nber.org/papers/w24948.ack

NBER working papers are circulated for discussion and comment purposes. They have not been peer-reviewed or been subject to the review by the NBER Board of Directors that accompanies official NBER publications.

(C) 2018 Bank of England, circulated with permission All rights reserved. Short sections of text, not to exceed two paragraphs, may be quoted without explicit permission provided that full credit, including $\odot$ notice, is given to the source. 
Estimating the Elasticity of Intertemporal Substitution Using Mortgage Notches

Michael Carlos Best, James Cloyne, Ethan Ilzetzki, and Henrik Kleven

NBER Working Paper No. 24948

August 2018

JEL No. D1,D14,D15,E2,E21,E4,E43,H3,H31

\begin{abstract}
$\underline{\text { ABSTRACT }}$
Using a novel source of quasi-experimental variation in interest rates, we develop a new approach to estimating the Elasticity of Intertemporal Substitution (EIS). In the UK, the mortgage interest rate features discrete jumps - notches - at thresholds for the loan-to-value (LTV) ratio. These notches generate large bunching below the critical LTV thresholds and missing mass above them. We develop a dynamic model that links these empirical moments to the underlying structural EIS. The average EIS is small, around 0.1, and quite homogeneous in the population. This finding is robust to structural assumptions and can allow for uncertainty, a wide range of risk preferences, portfolio reallocation, liquidity constraints, present bias, and optimization frictions. Our findings have implications for the numerous calibration studies that rely on larger values of the EIS.
\end{abstract}

\begin{tabular}{|c|c|}
\hline Michael Carlos Best & Ethan Ilzetzki \\
\hline Department of Economics & London School of Economics \\
\hline Columbia University & Houghton Street \\
\hline 420 West 118 th Street & London WC2A $2 \mathrm{AE}$ \\
\hline $\begin{array}{l}\text { New York, NY } 10027 \\
\text { and NBER }\end{array}$ & e.ilzetzki@LSE.ac.uk \\
\hline michael.best@columbia.edu & $\begin{array}{l}\text { Henrik Kleven } \\
\text { Department of Economics }\end{array}$ \\
\hline James Cloyne & Princeton University \\
\hline Department of Economics & 238 Julis Romo Rabinowitz Building \\
\hline University of California, Davis & Princeton, NJ 08544 \\
\hline One Shields Avenue & and NBER \\
\hline $\begin{array}{l}\text { Davis, CA } 95616 \\
\text { and CEPR } \\
\text { and also NBER } \\
\text { jcloyne@ucdavis.edu }\end{array}$ & kleven@princeton.edu \\
\hline
\end{tabular}

A web appendix is available at http://www.nber.org/data-appendix/w24948 


\section{Introduction}

How responsive are households to changes in the intertemporal price of consumption? In standard economic models this response is governed by the Elasticity of Intertemporal Substitution (EIS). The EIS is a key parameter in economics as it plays a central role for a range of questions in macro, public finance, household finance, and asset pricing. Unfortunately, there exists no consensus on a reasonable value for this parameter due to limitations in data and research designs. The most cited estimates in the literature range between 0 and 2, which is an an enormous range in terms of its implications for intertemporal behavior and policy.

A fundamental difficulty in addressing this question is how to find exogenous variation in interest rates. Most studies rely on time series movements in interest rates, which are gradual and almost certainly endogenous to unobserved factors that affect consumption. Our starting point is a novel source of quasi-experimental variation in interest rates arising from the fact that UK banks offer notched mortgage interest schedules. That is, the mortgage interest rate features discrete jumps at critical thresholds for the loan-to-value (LTV) ratio. For example, the interest rate increases by almost $0.5 \mathrm{pp}$ on the entire loan when crossing the $80 \%$ LTV threshold. This creates very strong incentives to reduce borrowing to a level below the notch, thereby giving up consumption today in order to get a lower interest rate and more consumption in the future. Intuitively, the magnitude of such borrowing and consumption responses to interest rate notches is governed by the value of the EIS.

Our study is based on administrative mortgage data from the Financial Conduct Authority. The data cover the universe of household mortgages in the UK between 2008-2014, including rich information on mortgage contracts and borrower characteristics. The majority of UK mortgage products carry a relatively low interest rate for a period of 2-5 years after which a much higher reset rate kicks in, creating strong incentives to refinance at the time the reset rate starts to apply. This makes refinancing a common occurrence in the UK. We focus on the population of refinancers, because they allow for a clean assessment of borrowing and intertemporal consumption choices.

Specifically, because housing choices are pre-determined for refinancers, estimating LTV responses in this sample allows us to isolate borrowing choices from housing choices.

Figure 1 plots the LTV distribution for UK home refinancers around the different interest rate notches, depicted by vertical lines. There is large and sharp bunching below every notch along 
with missing mass above every notch, which provides direct evidence that borrowers respond to interest rates. A recent literature in public economics has developed approaches to translate such bunching moments into reduced-form price elasticities, mostly focusing on behavioral responses to taxes and transfers in static contexts (Saez 2010; Chetty et al. 2011; Kleven \& Waseem 2013). It remains an open question whether these bunching-based elasticities have any structural or external validity, and whether their interpretation is robust to allowing for dynamics (Kleven 2016). In this paper we consider an inherently dynamic decision context and take the bunching literature in a more structural direction.

Translating bunching moments - or indeed any quasi-experimental moment — into structural parameters that can be used for out-of-sample prediction requires a structural model (see Kleven 2016; Einav et al. 2015, 2017). We develop two different approaches. The first approach is based on a simple two-period model with no uncertainty, no portfolio choice, no liquidity demand, and several other simplifying assumptions. This model provides the most transparent way of translating a bunching moment into the EIS. The second approach is based on a rich stochastic lifecycle model that relaxes many of the simplifying assumptions made in the baseline model. This model is more realistic, but computationally more involved and thus more of a "black box". We show that these two approaches give essentially the same answer: the observed bunching at interest notches is consistent with a small EIS, around 0.1 . We present a battery of robustness checks to and extensions of the stochastic lifecycle model, which confirm our finding that the EIS is small.

How can the EIS be small given the observation of substantial bunching? What would the raw data have looked like if the EIS were larger? To answer these questions, Figure 2 compares the observed LTV distribution to a simulated LTV distribution based on our two-period model with an EIS set equal to one (log preferences). These distributions are starkly different. The simulated distribution has zero mass above the 70\% LTV threshold, except at the notches. The simulated distribution has smaller bunching at the highest notches (80\% and $85 \%)$ and much larger bunching at the lowest notches $(60 \%, 70 \%$ and $75 \%)$. The fact that there is smaller bunching at the top reflects that, under an EIS of one, some homeowners jump across multiple notches and therefore skip the top notches entirely. We will show that the observed data is not consistent with such multiple-notch jumps. The stark contrast between the observed and simulated distributions suggests that the data is inconsistent with standard assumptions about the elasticity of intertemporal substitution.

A key question for identification is whether we can close the gap between the observed and simulated distributions through other means than a small EIS. As we show in the paper, it is not 
possible to close the gap by changing parameters and assumptions within a framework of frictionless household optimization. Rather, the only threat to identification is the presence of optimization frictions that attenuate bunching. Some borrowers may be stuck at LTV ratios above a notch, not because of true intertemporal preferences, but because they do not pay attention to or understand the incentives created by the notch. However, an important advantage of notch-based identification is that the missing mass just above the threshold is directly informative of optimization frictions. As shown by Kleven \& Waseem (2013), it is possible to correct for frictions using missing mass in dominated regions just above notches. We develop a structural extension of the Kleven-Waseem friction approach, showing that optimization frictions in this setting are not sufficient to justify large values of the EIS.

Our paper contributes to three literatures. First, we contribute to a large structural literature studying intertemporal substitution in consumption, reviewed by Attanasio \& Weber (2010). This literature estimates consumption Euler equations using either aggregate data (e.g., Hall 1988; Campbell \& Mankiw 1989) or micro survey data (e.g., Zeldes 1989; Attanasio \& Weber 1993, 1995; VissingJørgensen 2002; Gruber 2013). Most of the literature has relied on time series movements in interest rates, producing a very wide range of estimates depending on the analysis sample and empirical specification. ${ }^{1}$ The main conceptual differences between our approach and this literature is that we use interest rate notches at a point in time as opposed to interest rate changes over time, and that our estimating equation is not a standard Euler equation due to the discontinuous nature of the notched incentive. Our EIS estimates are at the lower end of the spectrum provided by these non-experimental studies. ${ }^{2}$

Second, we contribute to a reduced-form literature studying borrowing responses to the aftertax interest rate. This literature includes a number of natural experiment studies using variation in the after-tax interest rate created by taxes, subsidies, and regulation (e.g. Follain \& Dunsky 1997; Ling \& McGill 1998; Dunsky \& Follain 2000; Martins \& Villanueva 2006; Jappelli \& Pistaferri 2007; DeFusco \& Paciorek 2017). ${ }^{3}$ The range of estimates is very wide, from a zero effect in Jappelli \& Pistaferri (2007) to elasticities of about 1 in Dunsky \& Follain (2000) and 1.5-3.5 in Follain \& Dunsky

\footnotetext{
${ }^{1}$ A methodological exception is Gruber (2013) who uses cross-sectional and time series variation in capital income tax rates to identify the EIS and obtains very large estimates of about 2.

${ }^{2}$ Havránek (2015) conducts a meta analysis of the existing literature and finds estimates centered around 0.3-0.4, after controlling for publication bias.

${ }^{3}$ Related to our empirical approach, DeFusco \& Paciorek (2017) estimate leverage responses using an interest notch created by the conforming loan limit in the US, although their estimates do not separate mortgage demand from housing demand as we do here. Most importantly, they do not pursue the analysis of structural parameters, which is the main contribution of our paper.
} 
(1997). We estimate reduced-form borrowing elasticities around 0.5. A conceptual contribution of our paper is to characterize the relationship between reduced-form borrowing elasticities and the structural EIS, demonstrating that the former by itself is not very informative about the latter. The translation between the two parameters is mediated by additional (endogenous) variables that can vary widely across borrower populations. ${ }^{4}$

Third, we contribute to the recent bunching literature in public economics (as reviewed by Kleven 2016). Most of this literature has focused on static contexts and reduced-form estimation. By combining a bunching approach with dynamic structural estimation, our paper is related to recent work by Einav et al. $(2015,2017)$ who analyze bunching at a kink point in US Medicare. They argue that the choice of model is crucial when translating bunching into a parameter that can be used for out-of-sample prediction. In particular, they highlight the role played by frictions in the form of lumpiness and randomness in the choice variable used to bunch. ${ }^{5}$ This contrasts with our finding that the structural EIS ("out-of-sample prediction") is robust to the modeling assumptions we make. This difference can be explained mainly by a conceptual difference between kink-based and notch-based estimation. In the case of notches, the amount of friction is directly accounted using an observational moment - the amount of missing mass above the notch — as opposed making parametric assumptions about such frictions.

The paper is organized as follows. Section 2 describes the institutional setting and data, Section 3 characterizes the link between bunching, reduced-form elasticities, and the EIS in our baseline two-period model, Section 4 presents empirical results using the baseline model, Section 5 develops and structurally estimates our full stochastic lifecycle model, and finally Section 6 concludes.

\section{Institutional Setting, Data and Descriptives}

\subsection{UK Mortgage Market}

The UK mortgage market has several institutional features that facilitate our analysis. First, the interest rate on mortgage debt follows a step function with discrete jumps — notches - at certain LTV

\footnotetext{
${ }^{4}$ This finding echoes insights from early calibration studies, which showed that a given value of the EIS can imply widely different, but typically much larger, savings elasticities depending on other calibrated parameters (Summers 1981; Evans 1983).

${ }^{5}$ As discussed by Kleven (2016), this general insight echoes findings elsewhere in the bunching literature showing that the conversion of observed bunching (at kinks) into a structural elasticity is very sensitive to the assumed model of optimization frictions (e.g., Saez 1999; Chetty et al. 2010, 2011; Gelber et al. 2017).
} 
thresholds. There are interest rate notches at LTVs of $60 \%, 70 \%, 75 \%, 80 \%$, and $85 \%{ }^{6}$ When a borrower crosses one of these thresholds, the interest rate increases on the entire loan. The thresholds apply to the LTV ratio at the time of loan origination; the interest rate does not change as amortization or house price growth gradually reduces the LTV. The size of the interest rate jump at a given threshold varies across product types and over time. ${ }^{7}$ The notches are very salient: daily newspapers display menus of interest rates by bank and LTV bracket, and the LTV thresholds feature very prominently when shopping for mortgages. For example, the mortgage websites of all the major banks show LTV brackets and interest rates for their different products up front. ${ }^{8}$

Second, most UK mortgage products come with a relatively low interest rate for an initial period — typically 2, 3, or 5 years - after which a much larger (and variable) reset rate starts to apply. The notched interest rate schedule described above applies to the rate charged during the initial period of 2-5 years as opposed to the rate charged over the entire term of the mortgage (typically 25-35 years). The large and variable reset rate creates a very strong incentive to refinance at the end of the initial lower-rate period. This makes refinancing a frequent occurrence in the UK. In this paper we focus specifically on refinancers as this will allow us to isolate borrowing choices from housing choices, which is critical when assessing intertemporal consumption substitution.

Third, while borrowers have a strong incentive to refinance no later than at the onset of the reset rate, the cost of early refinancing means that there is also a strong incentive to refinance no sooner than this time. Specifically, UK mortgage contracts feature large pre-payment charges (often 5-10\% of the outstanding loan) on borrowers who refinance before reset rate onset. The combination of penalizing reset rates and heavy pre-payment charges implies that households have strong incentives to refinance right around the end of the initial lower-interest period.

To confirm that households act on these refinancing incentives, Figure A.1 shows the distribution of time-to-refinance in our data. The distribution features large excess mass in refinancing activity

\footnotetext{
${ }^{6}$ There is in principle also an interest notch at $90 \%$. However, very few banks offered mortgages above $90 \%$ after the financial crisis, implying that this threshold became a corner solution rather than a notch for most borrowers in our data. Our empirical analysis therefore focuses on the notches below $90 \%$.

${ }^{7}$ There is also some - but much less - variation in the size of notches across banks within product type and time. In particular, some banks do not feature certain notches at some points in time, but we show later that such no-notch observations represent a very small fraction of the data.

${ }^{8} \mathrm{~A}$ broad question not addressed in this paper is why UK banks impose such notched interest rate schedules, a type of question that often arises in settings with notched incentive schemes (Kleven 2016). The traditional explanation for upward-sloping interest rate schedules is that the default risk is increasing in leverage, either due to increasing risk for each borrower or due to adverse changes in the mix of borrowers. However, under the reasonable assumption of smoothly increasing default rates, standard models predict smoothly increasing interest rates. While the UK practice of implementing the increasing interest rate schedule as a step function may not be second-best efficient in standard models, it may be explained - as with other types of notches - by the simplicity and salience of notches to banks and their customers. Our empirical analysis of these notches is implicitly based on the assumption that default rates (in the absence of notches) are smooth around the threshold.
} 
around 2,3, and 5 years, consistent with the fact that these are the most common timings of the penalizing reset rate. The lightly shaded bars indicate the fraction of households in each monthly bin who refinance "on time", i.e. around the time their reset rate kicks in. These bars show that the majority of households refinance around reset rate onset and that this can explain the excess mass at 2,3 and 5 years. ${ }^{9}$ Note that this graph represents clear evidence that borrowers respond to interest rate changes, but on a different margin (refinance timing) than our main focus (borrowing and consumption). What is more, the empirical patterns documented here imply that the time of refinancing is effectively locked in by the reset rate structure. This is helpful for ruling out selection issues from endogenous refinance timing in the analysis below.

\subsection{Data}

Our analysis uses a novel and comprehensive administrative dataset containing the universe of mortgage product sales in the UK. ${ }^{10}$ This Product Sales Database (PSD) is collected by the Financial Conduct Authority for regulatory purposes and has information on mortgage originations back to April 2005. This includes detailed information on the mortgage contract such as the loan size, the date the mortgage became active, the valuation of the property, the initial interest rate charged, whether the interest rate is fixed or variable, the end date of the initial interest rate (the time at which the higher reset rate starts applying), whether the mortgage payments include amortization, and the mortgage term over which the full loan will be repaid. The data also include a number of borrower characteristics such as age, income, whether the income is solely or jointly earned, whether the borrower is a first-time buyer, mover or refinancer, and the reason for the refinance. There are also some characteristics of the property such as the type of dwelling and the number of rooms.

While we observe the borrower's LTV ratio, the PSD does not include information on product origination fees. These fees, while small relative to the loan size, can sometimes be rolled into the loan without affecting the LTV statistic used to determine the borrower's interest rate. For example, it is possible to observe an actual LTV ratio of 75.01\% where the borrower was still offered the product with a maximum LTV of $75 \%$. In order to address this, we exploit information on all mortgage products (including origination fees) in the UK available from the organization MoneyFacts

\footnotetext{
${ }^{9}$ Indeed, we observe only around a quarter of households not refinancing on time.

${ }^{10}$ The FCA Product Sales Database covers regulated mortgage contracts, which represent the majority of home finance products in the UK. The database does not cover home finance products such as home purchase plans, home reversions, second-charge lending, and buy-to-let mortgages.
} 
between 2008Q4 and 2014Q4. ${ }^{11}$ For a mortgage observation in the PSD, we find the corresponding product in MoneyFacts based on the lender, the date of the loan, the mortgage type, and the interest rate. Where the interest rate paid accords with an LTV bracket just below the actual LTV in the PSD data, we subtract the product fee from the observed loan value. Inspecting such individuals, the loan amount in excess of the threshold often corresponds precisely to the product fee. As a result, this adjustment places most of these individuals exactly at the notch. While this matching exercise reduces the sample, it is crucial for our methodology that the LTV ratio we use corresponds exactly to the one determining the actual interest rate.

Another useful feature of the PSD is that we are able to observe whether the household is refinancing. Using information about the characteristics of the property and the borrower, we can match refinancers over time in order to construct a panel. ${ }^{12}$ As described later, the panel structure allows us to implement a novel approach for estimating the counterfactual LTV distribution absent notches. The refinancer panel will therefore be the baseline dataset for our analysis.

Table 1 shows a range of descriptive statistics in different samples. Column 1 includes the full sample of mortgages sold between 2008Q4 and 2014Q4 where we can exploit fee information from MoneyFacts. The full sample contains around 2.8 million observations. Column 2 shows how the sample characteristics change when we restrict attention to refinancers. The descriptive statistics are very similar, although the LTV and LTI ratios are slightly lower for refinancers as one would expect. Column 3 shows the descriptive statistics in the panel of refinancers that we use in the empirical analysis. In moving from column 2 to 3, we lose refinancers for whom we lack sufficient information on their previous loans as well as those we are not able to match up over time. Our estimation sample still includes over 550,000 mortgages. Importantly, the descriptive statistics are very stable across the three columns, suggesting that our estimation sample (column 3) has similar average characteristics as the full population of borrowers.

\subsection{Interest Rate Jumps at Notches}

As described above, the UK mortgage market features discrete interest rate jumps at critical LTV thresholds, namely at $60 \%, 70 \%, 75 \%, 80 \%$, and $85 \%$. The first step of our analysis is to estimate the size of these interest rate notches. Unlike standard bunching approaches in which the discontinuity is the same across agents, in our setting the interest rate notch varies by bank, mortgage product,

\footnotetext{
${ }^{11}$ See www.moneyfacts.co.uk.

${ }^{12}$ For each homeowner we use the location of their house by 6-digit postcode (a code that covers a very small geographical area, around 15 homes on average) and the date of birth of the homeowner.
} 
and the time of loan origination (all of which we observe). As we will show, notches do not depend on individual characteristics conditional on bank, product, and time, which is important for ruling out selection bias in the estimated interest notches. This is because the UK mortgage market works like a mortgage supermarket in which banks offer their interest rate schedule on a given product to all borrowers who meet their lending standards, as opposed to entering into individual negotiations that depend on idiosyncratic factors.

Our empirical analysis will be based on the average interest rate jump at each notch conditional on bank, product, and time. We estimate these interest rate jumps non-parametrically using the following regression:

$$
r_{i}=f\left(L T V_{i}\right)+\beta_{1} \text { bank }_{i}+\beta_{2} \text { variability }_{i} \otimes \text { duration }_{i} \otimes \text { month }_{i}+\beta_{3} \text { repayment }_{i}+\beta_{4} \text { term }_{i}+\nu_{i}
$$

where $r_{i}$ is the nominal mortgage interest rate for individual $i, f($.$) is a step function with steps at$ each $0.25 \mathrm{pp}$ of the LTV ratio, bank $_{i}$ is a vector of bank dummies, variability ${ }_{i}$ is a vector of interest variability dummies (fixed interest rate, variable interest rate, capped interest rate, and "other"), duration $_{i}$ is a vector of dummies for the duration of the initial low-interest period (the time until the reset rate kicks in), month $_{i}$ is a vector of dummies for the month in which the mortgage was originated, repayment ${ }_{i}$ is a vector of dummies for the repayment type (interest only, capital and interest, and "other"), and term $i$ is a vector of dummies for the total term length. We denote by $\otimes$

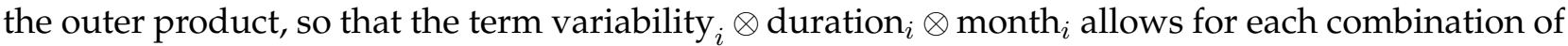
interest rate variability and duration to have its own non-parametric time trend.

Figure 3 plots the conditional interest rate as a function of LTV based on specification (1). In each LTV bin we plot the coefficient on the LTV bin dummy plus a constant given by the predicted value $E\left[\hat{r}_{i}\right]$ at the mean of all the other covariates (i.e., omitting the contribution of the LTV bin dummies). The figure shows that the mortgage interest rate evolves as a step function with sharp jumps at LTV ratios of $60 \%, 70 \%, 75 \%, 80 \%$, and $85 \%$. These interest jumps are larger at LTV thresholds higher up in the distribution. At the two top thresholds, the annual interest rate increases by almost 0.5pp. Importantly, the interest rate schedule is flat between notches. This implies that, conditional on product and bank characteristics, the mortgage interest rate is almost fully determined by the LTV notches we exploit.

The flatness of the interest schedule between notches suggests that individual characteristics (that vary by LTV) have no effect on the mortgage interest rate. Figure A.2 in the appendix verifies this by controlling for the individual characteristics we observe (such as age, income, and family 
status) in the estimation of the interest schedule. The figure shows that the results are virtually unchanged. If observables such as age and income do not matter for the interest notches, it is difficult to imagine any unobservables that would matter. These results confirm the institutional context described earlier, namely that the UK mortgage market works as a mortgage supermarket in which a given type of product is offered at a given price, independently of who buys it. ${ }^{13}$

When estimating the interest jumps from the coefficients on the LTV bin dummies in equation (1), we are holding all non-LTV mortgage characteristics constant on each side of the LTV threshold. For example, if a household is observed in a 5-year fixed rate mortgage (in a particular bank and month) just below the notch, we are asking how much higher the interest rate would have been for that same product just above the notch. In practice, if the household did move above the notch, it might decide to re-optimize in some of the non-LTV dimensions - say move from a 5-year fixed to a 2-year fixed rate - and this would give a different interest rate change. However, not only are such interest rate changes endogenous, they are conceptually misleading due to the fact that the non-interest characteristics of the mortgage have value to the borrower and are priced into the offered interest rate. Our approach of conditioning on non-LTV characteristics when estimating the interest rate schedule is based on a no-arbitrage assumption: within a given LTV bin, if lower-interest rate products or banks are available, in equilibrium this must be offset by less favorable terms in other dimensions. In this case, the within-product interest rate jump around the threshold is the right measure of the price incentive.

\subsection{Actual vs Counterfactual LTV Distributions}

The interest rate notches described above create strong incentives for borrowers to choose LTVs just below one of the notches, giving rise to bunching below the critical LTV thresholds and missing mass (holes) above them. We have already seen in Figure 1 that bunching and missing mass are indeed features of the data. The idea of our approach is to use these empirical moments to identify the EIS.

To quantify the amount of bunching and missing mass in the observed LTV distribution, we need an estimate of the counterfactual LTV distribution - what the distribution would have looked like without interest rate notches - and the public finance literature has developed approaches to

\footnotetext{
${ }^{13}$ Moreover, the global interest estimations shown in Figures 3 and A.2 understate flatness between notches compared to the more precise local estimations used later. The locally estimated interest schedules are essentially completely flat. This implies that "donut hole" approaches in which we exclude observations in a range around the threshold when estimating the interest rate jump give virtually unchanged results.
} 
obtain such counterfactuals (see Kleven 2016). The standard approach is to fit a flexible polynomial to the observed distribution, excluding data around the notch, and then extrapolate the fitted distribution to the notch (Chetty et al. 2011; Kleven \& Waseem 2013). However, this approach is not well-suited for our context: it it based on the assumption that notches affect the distribution only locally, which may be a reasonable assumption when there is only one notch or if the different notches are located very far apart. This is not satisfied in our setting in which we have many notches located relatively close to each other, and where Figure 1 suggests that most parts of the distribution are affected by notches. For example, it would be difficult to evaluate the counterfactual density at the $75 \%$ LTV notch using observations further down the distribution, say around $70 \%$, because those observations are distorted by other notches.

To resolve this issue, we propose a new approach to assess the counterfactual distribution that exploits the panel structure of the refinancer data. Based on the LTV in the previous mortgage, the amortization schedule, and the house value at the time of refinance (which is assessed by the bank), we measure the new LTV before the refinancer has taken any action. We label this the passive LTV as it would be the LTV if the homeowner simply rolled over debt between the two mortgage contracts. We will base our estimate of the counterfactual LTV on the passive LTV with an adjustment that we describe below.

In Panel A of Figure 4 we compare the actual LTV distribution to the passive LTV distribution. We see that the passive LTV distribution is smooth: unlike the actual LTV distribution it features no excess bunching or missing mass around notches. In general, the two distributions in Figure 4A may be different for two reasons: (i) behavioral responses to notches, and (ii) equity extraction or injection that would have happened even without notches. The second effect does not create bunching or missing mass, but it may smoothly shift the distribution. In this case, the passive LTV distribution would not exactly capture the counterfactual LTV distribution. To gauge the importance of such effects, we use information on equity extracted among households who do not bunch at notches. ${ }^{14}$ Figure A.3 shows that equity extracted among non-bunchers is positive through most of the passive LTV distribution (except at the very top) and has a smooth declining profile. We adjust the passive LTV distribution for non-bunching effects on LTV using the profile of equity extracted in Figure A.3. The assumption we are making is that the equity extraction profile among non-bunchers is a good proxy for the equity extraction profile in the full population of refinancers (including bunchers) in the counterfactual scenario without notches. We relax this assumption below.

\footnotetext{
${ }^{14}$ Where we define bunchers as those with LTVs within $0.25 p p$ below a notch, and non-bunchers as their complement.
} 
Our estimate of the counterfactual LTV distribution is shown in Panel B of Figure 4. Comparing the actual and counterfactual LTV distributions provides clear visual evidence of bunching and missing mass around each notch. Notice that, except for the region below the bottom notch at $60 \%$, the actual and counterfactual distributions never line up. This is because the actual distribution below each notch is affected by missing mass due to a notch further down. This implies that the standard approach to obtaining the counterfactual — fitting a polynomial to the observed distribution, excluding data right around the notch - would produce biased estimates in our context.

The assumption that the equity extraction profile among non-bunchers is a good proxy for the counterfactual equity extraction profile among bunchers raises potential concerns about selection. It is possible that bunchers are selected on variables that would impact their counterfactual equity extraction. We address this concern in two ways. First, a straightforward extension of our approach is to control for selection on observables: income, age, family status, and the number of past and future bunching episodes. The last of these covariates intends to capture the possibility that bunchers at time $t$ may be a selected sample of "optimizers" (thus bunching more at other times as well) while non-bunchers may be a selected sample of "passives". ${ }^{15}$ We regress equity extracted among non-bunchers on these covariates and predict equity extraction for both bunchers and non-bunchers from this regression. This approach makes virtually no difference to any of our results. Hence, if selection were an issue for our equity extraction adjustment, it would have to come from unobservables that impact equity extraction and are uncorrelated with (and therefore not picked up by) the observables that we do control for.

Second, we use a sample selection framework that does allow for selection on unobservables. Households' equity extraction decision $E=X^{\prime} \gamma+\nu$ depends on a set of observables $X$ and unobservables captured in $\nu$. Their bunching decision $B$ also depends on observables $X$ and an unobservable term $u: B=\mathbf{1}\left\{X^{\prime} \beta+u>0\right\}$. If the unobservable determinants of equity extraction and bunching are correlated $(\mathbb{E}[\nu \mid u, X] \neq 0)$, then estimating equity extraction using only data on non-bunchers will yield biased predictions of the counterfactual equity extraction of bunchers. To get unbiased predictions of counterfactual equity extraction, we need to estimate and include a selection correction term in our equity extraction equation. Under the assumptions that $u \sim \mathcal{N}(0,1)$ and $\mathbb{E}[\nu \mid u]=\delta u$ for some constant $\delta$, we obtain the classic Heckman (1979) sample selection framework and we can estimate equity extraction using a standard two-step procedure. We use flexible

\footnotetext{
${ }^{15}$ However, it turns out that the number of previous/future bunching events is not excessively large for households currently bunching. Figure A.5 in the appendix shows the average number of past/future bunching events at each value of current chosen LTV. The graph is smoothly increasing and features no spikes at at notches. This suggests that bunching households are not different "types" in terms of their general propensity to bunch or optimize.
} 
functions of the same covariates as above, and interact them with bins of passive LTV to form our observables $X$. In the first step, we estimate a probit model of the bunching decision and calculate inverse mills ratios of the bunching probability for each household $\hat{\lambda}\left(X^{\prime} \beta\right)$. In the second step, we run a regression of equity extraction on the observables and a sample selection correction term $E_{i}=X_{i}^{\prime} \gamma+\delta \hat{\lambda}\left(X_{i}^{\prime} \beta\right)+\eta_{i}$ on the sample of non-bunchers. These coefficients allow us to form selection-corrected predictions of equity extraction that we use to obtain the counterfactual LTV distribution.

Figure A.4 in the appendix compares the selection-corrected counterfactual to the baseline (nonbuncher based) counterfactual. The two distributions are very similar, appearing almost on top of each other throughout most of the distribution. The selection-corrected counterfactual is slightly above the baseline counterfactual around the mode of the distributions (between $70 \%$ and $75 \%$ ), but overall they are very similar. As we show later, the selection-correction approach makes virtually no difference to any of our results, and so we conclude that selection is unlikely to be an issue for our results. ${ }^{16}$

Finally, we note that the observed LTV distribution features a small spike at an LTV of $65 \%$, although this threshold is not associated with an interest notch. This spike is most naturally explained by round-number bunching, a phenomenon observed across a wide range of settings (see Kleven 2016). If we do not adjust for round-number bunching, the amount of excess mass at interest notches (all of which are located at round numbers) would overstate the true response to interest rates. While we could adjust for round-number bunching using the observed spike at $65 \%$, a concern may be that round-number bunching is different in different parts of the LTV distribution. Instead, we deal with this issue by exploiting that some banks at some points in time do not feature a specific notch. This allows us to net out round-number bunching at a given notch using bunching at that same threshold in a no-notch subsample. As we show in Section 4, this adjustment has only a minor impact on our results.

\section{A Simple Structural Model}

In this section we develop an approach to estimating the EIS using bunching at interest rate notches. The approach is based on a two-period model in which we make many simplifying assumptions.

\footnotetext{
${ }^{16} \mathrm{~A}$ fundamental reason why the counterfactual distribution is very robust to the equity extraction adjustment is that we are adjusting a distribution — the passive LTV distribution - that is relatively flat. If the passive LTV distribution had been completely flat, any shift to the left or right would have precisely zero impact on the bunching estimation.
} 
The virtue of this model is to provide a simple and transparent mapping between an observed bunching moment and the underlying structural EIS. In Section 5 we show that the estimates are robust to extending the analysis to a rich stochastic lifecycle model.

\subsection{The Mapping Between Bunching and the EIS}

We consider households who live for two periods (0 and 1) and have perfect foresight. They are homeowners and have chosen to remain in their current dwellings in both periods, but face a mortgage refinancing choice at time zero. As a baseline, assume that they can refinance at a constant gross borrowing rate equal to $R$ (i.e., there is no notch).

The utility of consuming housing services $H_{t}$ is separable from the utility of consuming nondurable goods $c_{t}$, and households place no value on residual wealth (e.g. bequests) at the end of period 1. Households value non-housing consumption in any period $t$ via a constant EIS function $\frac{\sigma}{\sigma-1} c_{t}^{\frac{\sigma-1}{\sigma}}$ and discount the future by a factor $\delta$. Hence, the lifetime utility derived from non-housing consumption is given by $\frac{\sigma}{\sigma-1}\left(c_{0}^{\frac{\sigma-1}{\sigma}}+\delta c_{1}^{\frac{\sigma-1}{\sigma}}\right)$.

The households receive an exogenous stream of income, $y_{t}$ in period $t$. They have initial net wealth $W_{0}$ equal to housing wealth net of any mortgage debt and net of any refinancing costs incurred in period zero. For simplicity, we assume that households hold no assets other than housing and have no liabilities other than the mortgage. The budget constraint in period 0 is therefore given by

$$
c_{0}=y_{0}+W_{0}-(1-\lambda) P_{0} H,
$$

where $\lambda$ is the LTV of the new mortgage and $P_{0} H$ is housing value (using that $H_{0}=H_{1}=H$ ). The period-1 budget constraint is given by

$$
c_{1}=y_{1}-R \lambda P_{0} H+(1-d) P_{1} H
$$

where $d$ is the rate of house depreciation and $P_{1}$ is the house price in period 1.

Households choose consumption according to the standard Euler equation

$$
c_{1}=(\delta R)^{\sigma} c_{0} .
$$

Equations (2)-(4) determine the choice of $c_{0}, c_{1}$, and $\lambda$ as functions the exogenous parameters of the model. We note that the LTV choice $\lambda$ is monotonically decreasing in initial wealth $W_{0}$ and the 
interest rate $R .{ }^{17}$

To begin with, we simplify by assuming that households are heterogeneous only in $W_{0}$. Our general argument goes through if households are heterogeneous in other dimensions such as income, housing quality, or preferences. Below we analyze the important case where the EIS parameter itself is heterogeneous. If $W_{0}$ is smoothly distributed in the population, equations (2)-(4) imply a smooth density distribution of LTV, which we denote by $f_{0}(\lambda)$. We will refer to this as the counterfactual LTV distribution under a constant interest rate $R$. Our estimate of the empirical counterpart to $f_{0}(\lambda)$ was shown in Figure 4.

Suppose now that an interest rate notch is introduced at $\lambda^{*}$, so that the borrowing rate jumps from $R$ to $R+\Delta R$ for LTVs exceeding $\lambda^{*}$. Figure 5 illustrates the implications of this notch for borrowing and consumption. Panel A depicts the period-1 budget constraint before and after the introduction of the notch in $\left\{\lambda, c_{1}\right\}$ space. It also shows the indifference curves before and after the notch for the marginal bunching household, i.e. the highest-LTV (lowest-wealth) household who will choose to bunch at the notch. ${ }^{18}$ When faced with the constant interest rate $R$, this household chooses an LTV of $\lambda^{*}+\Delta \lambda$, where the indifference curve is tangent to the initial budget constraint. After the introduction of the notch, this household is indifferent between locating at the LTV threshold $\lambda^{*}$ and locating at the best interior LTV $\lambda^{I}$, where the indifference curve is tangent to the notched budget constraint. All households whose LTV fell in the segment $\left[\lambda^{*}, \lambda^{*}+\Delta \lambda\right]$ absent the notch are strictly better off bunching than staying at an interior LTV.

Panel B shows the LTV distribution before and after the notch. In the presence of the notch, there is sharp bunching at $\lambda^{*}$ along with a hole in the distribution between $\left(\lambda^{*}, \lambda^{I}\right)$. The amount of bunching is equal to $B=\int_{\lambda^{*}}^{\lambda^{*}+\Delta \lambda} f_{0}(\lambda) d \lambda \simeq f_{0}\left(\lambda^{*}\right) \Delta \lambda$. Hence, with estimates of excess bunching $B$ and the counterfactual density around the notch $f_{0}\left(\lambda^{*}\right)$, it is possible to estimate the LTV response $\Delta \lambda$. The fundamental idea of our approach - a dynamic extension of Kleven \& Waseem (2013) is that we can use the indifference condition between $\lambda^{*}$ and $\lambda^{I}$ for the marginal buncher to derive a relationship between the LTV response $\Delta \lambda$ and the EIS $\sigma$.

To characterize the estimating indifference equation, we first use that the marginal bunching household chooses the LTV ratio $\lambda^{*}+\Delta \lambda$ in the counterfactual scenario with a constant interest rate

\footnotetext{
${ }^{17}$ The first effect follows from the fact that consumption in period 1 is a normal good and therefore increasing in initial wealth $W_{0}$. Initial wealth can increase $c_{1}$ only via a decrease in borrowing in period 0 . The second effect follows from the fact that the wealth and substitution effects of the interest rate push in the same direction here. Given that the household is a borrower, an increase in the interest rate reduces lifetime wealth and thus consumption in both periods. Reducing consumption in period 0 requires a reduction in debt. The substitution effect follows from the fact that an increase in the interest rate increases the relative price of consumption in period 0 (or equivalently the relative cost of debt).

${ }^{18}$ Indifference curves can be plotted in in $\left\{\lambda, c_{1}\right\}$ space using the period- 0 budget constraint.
} 
$R$. From equations (2)-(4), this allows us to relate initial wealth $W_{0}$ for this household to the other parameters of the model as follows

$$
W_{0}=P_{0} H-y_{0}+\frac{y_{1}+(1-d) P_{1} H-\left((\delta R)^{\sigma}+R\right)\left(\lambda^{*}+\Delta \lambda\right) P_{0} H}{(\delta R)^{\sigma}} .
$$

This relationship allows us to eliminate $W_{0}$ from the problem. This is helpful because our data do not contain information on non-housing assets and liabilities, and therefore do not enable us to measure total initial wealth.

Using wealth defined in equation (5) and the optimality conditions (2)-(4) evaluated at the interest rate $R+\Delta R$, we can solve for the lifetime utility of the marginal buncher at the best interior choice $\lambda^{I}$ in the presence of the notch. This is given by

$$
\begin{aligned}
V^{I}(\sigma, \delta, \Delta \lambda, \Delta R, \mathbf{x}) & =\frac{\sigma}{\sigma-1}\left(P_{0} H\right)^{\frac{\sigma-1}{\sigma}} \frac{\left(\delta^{\sigma}(R+\Delta R)^{\sigma-1}+1\right)^{\frac{1}{\sigma}}}{(\delta R)^{\sigma-1}} \times \\
& \left(\left(\frac{(\delta R)^{\sigma}}{R+\Delta R}+1\right)\left(\frac{y_{1}}{P_{0} H}+\Pi_{1}\right)-\left((\delta R)^{\sigma}+R\right)\left(\lambda^{*}+\Delta \lambda\right)\right)^{\frac{\sigma-1}{\sigma}},
\end{aligned}
$$

where $\Pi_{1} \equiv(1-d) \frac{P_{1}}{P_{0}}$ is gross house price growth net of depreciation. In the indirect utility function $V^{I}($.$) , the argument \mathbf{x}$ is a vector that includes the parameters $\left\{\lambda^{*}, R, \frac{y_{1}}{P_{0} H}+\Pi_{1}\right\}$.

Similarly, setting $\lambda=\lambda^{*}$ and applying the interest rate $R$, the budget constraints (2)-(3) and the wealth condition (5) allow us to evaluate lifetime utility at the notch as

$$
V^{N}(\sigma, \delta, \Delta \lambda, \mathbf{x})=\frac{\sigma}{\sigma-1}\left(P_{0} H\right)^{\frac{\sigma-1}{\sigma}}\left(\begin{array}{c}
\frac{1}{(\delta R)^{\sigma}}\left(\frac{y_{1}}{P_{0} H}+\Pi_{1}-R \lambda^{*}-\left((\delta R)^{\sigma}+R\right) \Delta \lambda\right)^{\frac{\sigma-1}{\sigma}} \\
+\delta\left(\frac{y_{1}}{P_{0} H}+\Pi_{1}-R \lambda^{*}\right)^{\frac{\sigma-1}{\sigma}}
\end{array}\right)
$$

The marginal buncher is indifferent between bunching at the notch and locating at the best interior LTV, allowing us to state the following proposition:

Proposition 1 (Estimating Indifference Equation). Given a bunching moment $\{\Delta \lambda, \Delta R\}$ and a discount factor $\delta$, the EIS $\sigma$ is the solution to the indifference equation

$$
F(\sigma, \delta, \Delta \lambda, \Delta R, \mathbf{x}) \equiv V^{N}(\sigma, \delta, \Delta \lambda, \mathbf{x})-V^{I}(\sigma, \delta, \Delta \lambda, \Delta R, \mathbf{x})=0
$$

where $\mathbf{x}=\left\{R, \lambda^{*}, \frac{y_{1}}{P_{0} H}+\Pi_{1}\right\}$, and where $V^{I}($.$) and V^{N}($.$) are given by (6) and (7), respectively.$

Proof. The proof is in Appendix B. 
Three points are worth highlighting. First, the indifference equation (8) is based on a setting with only one notch, while our empirical setting has multiple notches. In the presence of multiple notches, it is possible that bunchers move across more than one threshold at a time, and it is conceptually straightforward to modify the indifference equation to allow for this (see Kleven \& Waseem 2013). We focus on the single-notch equation here, because the data does not support the presence of multiple-notch jumps. We discuss this point in the next section.

Second, the indifference equation contains two structural parameters, the EIS $\sigma$ and the discount factor $\delta$. This suggests that we cannot identify $\sigma$ from a single bunching moment. However, it turns out that the value of $\sigma$ is extremely robust to assumptions about $\delta$. The intuitive reason is that the discount factor primarily governs the level of borrowing at any interest rate (i.e., it shifts the LTV distribution on both sides of the notch) and has only a minor impact on the response of borrowing to interest rate changes. By contrast, the EIS governs the curvature of intertemporal preferences, which directly impacts bunching responses. In section 3.3 we demonstrate this important identification argument using numerical simulations. ${ }^{19}$

Third, even in this simple dynamic model, the estimating indifference equation is considerably more involved than the static bunching estimator developed by Kleven \& Waseem (2013). The static bunching estimator does not require calibrating any variables: the bunching moment maps directly into a structural elasticity. The added complexity of the dynamic approach increases by an order of magnitude when we turn to the full stochastic lifecycle model in Section 5. However, as we will show, it is a general feature of our methodology that the calibrated variables have a very small impact on the estimating indifference equation, making our results robust despite the analytical complexity of the expressions. The intuitive reason is essentially the same as the one underlying the robustness to $\delta$.

The exposition above assumes that there is only one value of the structural EIS $\sigma$, while in practice there is likely to be heterogeneity in this parameter. In fact, the empirical LTV distribution shown in Figure 1 implies that this has to be the case: without heterogeneity, there would be a sharp hole in the LTV distribution between $\lambda^{*}$ and $\lambda^{I}$ as illustrated in Figure 5B, whereas the empirical LTV distribution features a gradual hole and has some refinancers located just above the notch. ${ }^{20}$

\footnotetext{
${ }^{19}$ Besides $\delta$, the only other value in equation (8) that requires calibration is $\frac{y_{1}}{P_{0} H}+\Pi_{1}=\frac{y_{1}+(1-d) P_{1} H}{P_{0} H}$. This is a measure of future resources from human wealth $\left(y_{1}\right)$ and housing wealth $\left((1-d) P_{1} H\right)$, scaled by current housing wealth. We estimate $\sigma$ using empirically reasonable values of this variable, but results are essentially unaffected by assumed parameter values (as for $\delta$, this is mainly a level effect rather than a response effect).

${ }^{20}$ Besides very small $\sigma$ s among some households, the presence of density mass just above the notch may reflect various optimization frictions (including liquidity constraints), an issue that we will address in Section 3.2.
} 
This provides prima facie evidence that some households have very small $\sigma$ s while others have larger $\sigma$ s. As Kleven \& Waseem (2013) and Kleven (2016) show, in the presence of heterogeneity in $\sigma$, our bunching approach estimates the average $\sigma$.

To see this, consider a joint distribution of initial wealth $W_{0}$ and the EIS $\sigma$. At each elasticity level $\sigma$, households optimize as characterized above. In the counterfactual scenario with a constant interest rate $R$, there is a joint distribution of LTV and EIS given by $g_{0}(\lambda, \sigma)$ and an unconditional distribution of LTV given by $g_{0}(\lambda)=\int_{\sigma} g_{0}(\lambda, \sigma) d \sigma$. In the observed scenario with a notched interest rate, the marginal buncher at elasticity level $\sigma$ reduces LTV by $\Delta \lambda_{\sigma}$. We can then link bunching $B$ to the average LTV response at the notch $E\left[\Delta \lambda_{\sigma} \mid \lambda^{*}\right]$ as follows

$$
B=\int_{\sigma} \int_{\lambda^{*}}^{\lambda^{*}+\Delta \lambda_{\sigma}} g_{0}(\lambda, \sigma) d \lambda d \sigma \simeq g_{0}\left(\lambda^{*}\right) E\left[\Delta \lambda_{\sigma} \mid \lambda^{*}\right]
$$

where the approximation assumes that the counterfactual density $g_{0}(\lambda, \sigma)$ is roughly constant in $\lambda$ on the bunching segment $\left(\lambda^{*}, \lambda^{*}+\Delta \lambda_{\sigma}\right)$. In other words, in the presence of heterogeneous treatment effects, bunching identifies a local average treatment effect. When applying a bunching moment like $E\left[\Delta \lambda_{\sigma} \mid \lambda^{*}\right]$ to the estimating indifference equation (8), we are estimating EIS at the average LTV response as opposed to the average EIS. These two will in general be different due to the nonlinearity of (8), creating a form of aggregation bias. As elaborated by Kleven (2016), such aggregation bias is likely to be very small in practice.

A large literature estimates reduced-form elasticities of borrowing or saving with respect to the interest rate. How does one compare the magnitude of such reduced-form elasticities to the EIS? We can use our framework to characterize the relationship between the two elasticity concepts. Denoting the elasticity of borrowing with respect to the interest rate by $\varepsilon$, comparative statics on (2) to (4) give the following result.

Proposition 2 (EIS vs Reduced-Form Borrowing Elasticity). Given the EIS $\sigma$, the discount factor $\delta$, the gross interest rate $R$, and the ratio $L T W \equiv \frac{P_{0} H-W_{0}-y_{0}}{y_{1}+(1-d) P_{1} H}$, the elasticity of borrowing with respect to the interest rate is given by

$$
\varepsilon=-\frac{\partial \log \lambda}{\partial \log R}=\frac{\sigma(\delta R)^{\sigma}+R}{(\delta R)^{\sigma}+R}-\frac{\sigma(\delta R)^{\sigma} \times L T W}{1+(\delta R)^{\sigma} \times L T W} .
$$

Proof. The proof is in Appendix B.

Besides the structural parameters $\sigma, \delta$ and the interest rate $R$, the reduced-form elasticity de- 
pends on a ratio we have defined as $L T W$. To get an intuitive sense of this ratio, consider a household whose only initial wealth is (the net worth of) housing and who has no current income. In that case, $W_{0}=\left(1-\lambda_{0}\right) P_{0} H$ and the ratio $L T W=\frac{\lambda_{0} P_{0} H}{y_{1}+(1-d) P_{1} H}$ represents a loan to future wealth ratio, with future wealth incorporating both human and financial (housing) wealth. For brevity, we refer to this ratio as a loan-to-wealth ratio. This ratio is endogenous and will in general differ substantially across households. ${ }^{21}$

Figure A.6 in appendix illustrates the mapping between the EIS and the reduced-form elasticity under different $L T W$ ratios. We see that the reduced-form elasticity can vary greatly for a given EIS, depending on $L T W$. Conversely, given an estimate of the reduced-form elasticity, there is very large variation in the EIS parameters that could be consistent with that estimate. This makes it difficult to infer the likely magnitude of the EIS from reduced-form evidence. ${ }^{22}$

\subsection{Optimization Frictions}

The model presented above assumes that there are no optimization frictions (such as inattention or misperception). However, some households may be prevented from bunching due to such frictions, in which case our estimate of $\sigma$ would be downward biased. To deal with this general problem in empirical research, Kleven \& Waseem (2013) developed a non-parametric frictions adjustment based on the presence of strictly dominated regions of behavior above notches. In their setting, strictly dominated regions above income tax notches were used to estimate the fraction of nonoptimizing agents, while being agnostic about the specific reasons for not optimizing. Assuming that the fraction of non-optimizers is the same outside the dominated region (i.e., where it cannot be directly measured), Kleven \& Waseem (2013) showed that it is possible to adjust the bunching estimates for the amount of optimization friction in order to estimate true structural elasticities.

Here we propose a parametric version of the Kleven-Waseem friction approach. In our setting, there are no strictly dominated regions per se. Locating immediately above an LTV notch implies a large drop in future consumption, but allows for (slightly) larger current consumption. If a consumer is perfectly impatient $(\delta=0)$, locating in such regions will be optimal. However, as long as consumers value future consumption at all $(\delta>0)$, there exists no non-negative elasticity of

\footnotetext{
${ }^{21}$ The result in Proposition 2 also implies that, when $\sigma$ converges to zero, the value of $\varepsilon$ converges to $R /(1+R)$. This is a lower bound on the reduced-form elasticity and represents the wealth effect. This particular result is driven by the twoperiod assumption. In appendix $C$, we generalize our results to a multi-period version of the baseline model (retaining the other simplifying assumptions of this model) and show that the pure wealth effect (lower bound on $\varepsilon$ ) is smaller in this case.

${ }^{22}$ In the numerical example presented in the figure (in which $\delta=R=1$ ), the reduced-form elasticity is bounded from below by $R /(1+R)=0.5$ corresponding to the pure wealth effect (see equation 10 for $\sigma=0$ ).
} 
intertemporal substitution $(\sigma \geq 0)$ that can justify locating immediately above an LTV threshold. Even with a zero substitution elasticity, the higher interest rate above the notch creates a wealth effect that should make consumers reduce consumption and leverage today, which is inconsistent with locating extremely close to the notch. Hence, we can structurally derive an LTV range above the notch that is inconsistent with any $\sigma \geq 0$. This range can be characterized as follows.

Proposition 3 (Dominated Region). Under any $\sigma \geq 0$, choosing an LTV at the notch point $\lambda^{*}$ dominates any interior $\operatorname{LTV} \lambda>\lambda^{*}$ for households whose counterfactual LTV satisfies

$$
\lambda^{*}+\Delta \lambda \in\left(\lambda^{*},\left(1+\frac{\Delta R}{R+1}\right) \lambda^{*}\right)
$$

Proof. The proof is in Appendix B.

We estimate the fraction of non-optimizers as the observed density mass in proportion to counterfactual density mass within the dominated region defined in (11). We assume that the fraction of non-optimizers in the dominated region is a good proxy for optimization frictions elsewhere in the distribution (where the amount of friction cannot be observed). Denoting the fraction of non-

optimizers by $a$, the friction-adjusted bunching mass equals $\frac{B}{1-a}$ and the frictionless LTV response equals $\frac{\Delta \lambda}{1-a}$. These are the reduced-form statistics that enter into the structural estimation of $\sigma$.

Finally, it is worth noting that the dominated regions from which we estimate $a$ are very small. As shown in Figure 3, the largest notch is at $\lambda^{*}=80 \%$ where the interest jumps by $\Delta R=0.5 \mathrm{pp}=$ 0.005. Using (11), this gives a dominated LTV range of approximately $(80 \%, 80.2 \%)$ for $R \simeq 1$. For example, someone located at an LTV of $80.1 \%$ and with a house worth $£ 200,000$ (the average house value around this notch) would have to inject only $£ 200$ in order to get the 0.5pp reduction in the annual interest rate on the entire mortgage (worth roughly $£ 3,000$ in lower interest payments). If the household does not take this investment opportunity, we attribute it to optimization friction.

\subsection{Identification of the EIS: Numerical Simulations}

As discussed above, it is not immediately apparent how the EIS can be identified from bunching, because the estimating indifference equation (8) contains other parameters: the discount factor, future house prices and future income. In this section we present simulations of the global LTV distribution under different parameter configurations, which illustrate that only the EIS can be used to fit the observed distribution. While other parameters play some role, their impacts on bunching responses are very minor. 
Figure 6 compares the observed LTV distribution to simulated LTV distributions under four different EIS scenarios. The other parameters of the model are assigned reasonable values that do not vary across the different EIS scenarios. ${ }^{23}$ The distribution of initial wealth $W_{0}$ is calibrated using equation (5) in order to replicate the counterfactual LTV distribution shown in Figure 4. In this counterfactual scenario, we assume that each borrower faces a flat interest rate $R$ given by the observed rate at the counterfactual location. ${ }^{24}$ Having calibrated the model in this way, the simulated LTV distribution is based on introducing the notched interest rate schedule and letting borrowers choose LTV optimally by comparing utility levels at their best interior location and at the five notch points.

The resulting distributions under each $\sigma$ is shown in the four panels of Figure 6. Panel A sets $\sigma=0.06$, corresponding to the EIS that minimizes the mean squared error (MSE) between the simulated bunching masses and the observed bunching masses. Panels B-D consider values of the EIS commonly used in the literature $(\sigma=0.5,1,2) .{ }^{25}$ The figure shows clearly why the data "demands" a low EIS. With higher elasticities, households grossly over-respond to the interest rate notches and often skip several notches in search of lower rates. As a result, the simulated distributions have almost no mass above the 70\% LTV threshold, except at the notch points. There is too little bunching at the highest notches (as borrowers tend to skip these notches) and too much bunching at the lowest notches. This contrasts with the simulated distribution under $\sigma=0.06$, which does a far better job of matching the data. ${ }^{26}$

While these results show that a low EIS can reconcile model and data, Figure A.7 in the appendix shows that a low EIS is the only way of reconciling the two. The top panel repeats the best fit from the previous figure, i.e. $\sigma=0.06$ with the other parameters set to realistic values. The lower panel instead sets $\sigma=1$ and calibrates all the other parameters (discount rate, house price growth and income growth) so as to minimize the MSE of the simulated bunching masses. Even when all the other parameters are fine-tuned to satisfy this single objective, the model provides a very poor fit to the data. This is because bunching responses are relatively insensitive to these other parameters. ${ }^{27}$

\footnotetext{
${ }^{23}$ Specifically, the discount factor is set at an annual rate of $\delta=0.96$ (a common value in the literature), real house price growth is set at an annual rate of $P_{1} / P_{0}=1.026$ (the historical average in the UK), the depreciation rate is set at $d=0.025$ (taken from the literature), while for simplicity real income is assumed to be constant over time $y_{1}=y_{0}$.

${ }^{24}$ That is, borrowers get individualized flat interest rates based on their counterfactual bracket location. Our results are insensitive to the specific assumption we make about the counterfactual interest rate level.

${ }^{25}$ Panel C $(\sigma=1)$ repeats the simulation shown in Figure 2 discussed earlier.

${ }^{26}$ The fit is quite impressive when considering the crudeness of assuming a single $\sigma$ throughout the LTV distribution. This assumption is relaxed in our local estimations presented below.

${ }^{27}$ We show in Section 5 that this remains true in a rich stochastic lifecycle model where several other parameters can be changed.
} 
What is more, calibrating the remaining parameters in this way leads to highly unrealistic values, including an annual discount rate of $\delta=0.24$ and annual income growth of $-60 \%$.

The only real threat to identification is the presence of optimization frictions such as inattention, inertia or misperception. While $\sigma$ is the only parameter that can close the gap between model and data within a frictionless model, a sufficient amount of friction would be another way of closing the gap. It is therefore crucial that we have an empirical handle on the amount of friction from the dominated regions. Using the approach laid out in the previous section, Figure A.8 in the appendix explores if there is enough optimization friction to justify a much higher value of the EIS. The figure is constructed like Figure 6, but the simulated LTV distributions have been adjusted to account for the presence of non-optimizers. Specifically, denoting by $a_{n}$ the fraction of households observed in the dominated region above notch $n$, the simulations assume that the fraction $a_{n}$ of housesholds between the notch $n$ and the next notch $n+1$ are stuck at their counterfactual LTV. This exercise creates less bunching at the notches and greater mass between the notches, but it does not fundamentally alter our conclusions. The EIS that provides the best fit is still small $(\sigma=0.12)$ and standard EIS values provide very poor fits. Therefore, while it is clearly important to account for optimization frictions, the dominated regions suggest that there is not nearly enough friction in our setting to justify large structural elasticities.

The simulation exercises presented here are useful for illustrating how bunching can identify the EIS and why the data calls for a small elasticity. However, these simulations do not yield precise estimates of the EIS, because they are based on fitting global distributions assuming that a single elasticity applies everywhere. The next section presents local bunching estimations (using the estimating indifference equation characterized above) in which we relax this assumption.

\section{Estimating the EIS: Simple Model}

\subsection{Bunching Estimation}

In this section we use bunching to estimate the EIS and the reduced-form borrowing elasticity based on the simple framework developed above. The next section extends the analysis to our full structural model.

We first consider all notches together by pooling the data into a single average notch. For each notch point $n$ and each mortgage $i$, we calculate a normalized LTV as $L T V_{i n}=L T V_{i}-n .^{28}$ We

\footnotetext{
${ }^{28}$ For example, a mortgage with an LTV of $73 \%$ has normalized LTVs of $L T V_{i 70}=3$ with respect to the $70 \%$ notch and
} 
then stack the normalized LTVs across the five notches and consider their distribution around the average notch at zero. This is shown in Figure 7 in which the actual LTV distribution is the series in black dots and the counterfactual LTV distribution is the series in orange crosses, with their frequencies in $0.25 \mathrm{pp}$ bins given on the left axis. The counterfactual is obtained using the panel method described in Section 2.4, with the global distribution shown in Figure 4. The figure also plots the pooled conditional interest rate at each LTV in green squares (right axis) obtained from the non-parametric regression described in Section 2.3. ${ }^{29}$ The graphs are shown with $95 \%$ confidence bands computed by bootstrapping. ${ }^{30}$

The figure displays the two key empirical moments that we will use later: the interest rate jump at the notch, $\Delta r$, and the amount of bunching scaled by the counterfactual density at the threshold, $b \equiv B /\left[g_{0}\left(\lambda^{*}\right) \times\right.$ binwidth $] .^{31}$ As shown in equation (9), this bunching statistic is approximately proportional to the local average LTV response. In the figure, we distinguish between two different bunching statistics: $b$ (raw) and $b$. The first estimate is based on the raw data shown in the figure, while the second (smaller) estimate adjusts for the presence of round-number bunching. As discussed earlier, we adjust for round-number bunching by using that some banks do not feature certain notches during certain periods. ${ }^{32}$

The following findings emerge from Figure 7. First, there is large and sharp bunching equal to five times the height of the counterfactual distribution at the notch, or about $10 \%$ less when accounting for round-number bunching. Second, there is a clear gap between the actual and counterfactual distributions to the right of the notch. This is the "hole" in which the bunching households would have been observed absent the notched interest rate schedule. The hole extends to around 3.5pp above the notch, implying that the most responsive households reduce their LTV by 3.5pp $L T V_{i 75}=-2$ with respect to the $75 \%$ notch.

${ }^{29}$ The pooled interest rate line is a weighted average of conditional interest rates from the regression (1) implemented locally around each notch.

${ }^{30}$ The bootstrap procedure draws 100 samples of mortgages from the observed sample, with replacement and stratifying by notch.

${ }^{31}$ We measure bunching $B$ as excess mass in the actual distribution relative to the counterfactual distribution in a $1 \mathrm{pp}$ range below the threshold, thus allowing for some overshooting by bunching households. Because bunching is extremely sharp in our setting, the results are very robust to reducing the width of this range.

${ }^{32}$ Figure A.9 in appendix shows the LTV distribution in the no-notch subsample, i.e. mortgages located close to one of the five thresholds in a bank-by-time cell that does not feature an interest notch at that threshold. Panel A of the figure shows that the no-notch subsample is a very small fraction of the full sample. Panel B of the figure zooms in on the no-notch subsample, demonstrating that there is a modest amount of round-number bunching. To adjust for roundnumber bunching, we estimate the degree of bunching at the notches using the no-notch subsample. As is common in the bunching literature, we estimate the counterfactual LTV distribution using a 5 th order polynomial fitted to the data collapsed into bins with a width of 0.25 percentage points and excluding data within $1 \%$ of the notch. We then subtract the estimated normalized bunching in the no-notch sample, $b_{R N}$, from the bunching moment of interest, $b_{r a w}$, to calculate our estimate of the bunching due to the interest rate notches. 
in response to the average interest rate notch of $0.25 \mathrm{pp}$. This upper-bound response is well below the next notch (and the confidence band is tight), validating our assumption in Proposition 1 that bunchers move only one notch.

Third, when comparing the actual and counterfactual densities immediately above the notch, we see that about $30 \%$ of borrowers are stuck in a dominated region. ${ }^{33}$ As discussed in section 3.2, we interpret the observed mass in the dominated region as a reflection of optimization frictions such as switching costs, inattention, and misperception. In this setting there is an additional reason for locating just above notches: the fact that some borrowers have mortgages in banks that do not feature that particular notch at the time of their loan origination. However, the impact of nonotch banks on the hole is limited by the fact that they represent a very small fraction of the data as mentioned above (see Figure A.9). Moreover, locating just above a threshold in a no-notch bank may in fact be viewed as an optimization friction in the form of bank switching costs. As Figure A.10 in the appendix shows, borrowers located above a threshold in a no-notch banks could typically get a large discount by switching to a similar product in a different bank and moving below the threshold, and their unwillingness to do so must be related either to a friction in bank choice or to unobserved services provided by the no-notch bank. When we adjust for optimization frictions using the dominated regions, we assume either that (i) all mass in the dominated region is due to friction or (ii) that only the mass coming from notched banks is due to friction.

Figure 8 shows bunching evidence for individual notches, but is otherwise constructed in the same way as the previous figure. The interest rate jumps shown in this figure are somewhat smaller than those reported in Figure 3, because the interest rate jumps shown here apply to the refinancer sample (as opposed to the full population of people with mortgages) and therefore to a different composition of mortgages. The evidence from the individual notches is qualitatively consistent with the evidence from the pooled notch. The amount of bunching $b$ is increasing in the size of the interest rate jump, and the amount of mass just above the notch (friction) is decreasing in the size of the jump, exactly as one would expect.

\subsection{Elasticity Estimation}

We turn to the estimation of the EIS in Table 2. The table shows results for the five individual notches and for the pooled notch. Panel A starts by summarizing the statistics presented so far: the interest rate level below each notch $r$, the interest rate jump $\Delta r$, and the bunching statistic $b$. The

\footnotetext{
${ }^{33}$ The dominated regions (as characterized in Proposition 3) are even smaller than the 0.25pp LTV bins depicted in the figure, but we show later that $30 \%$ is nevertheless about right.
} 
panel also shows the fraction of non-optimizers $a$ obtained from the dominated region, the frictionadjusted bunching statistic $b_{A d j}=b /(1-a)$, and the implied frictionless LTV response $\Delta \lambda_{A d j}$. The average LTV response using the pooled notch is close to $2 \mathrm{pp}$, i.e. households are willing to reduce borrowing by an average of 2 percent of their house value in order to avoid the interest jump of $0.25 \mathrm{pp}$. Apart from the $80 \%$ notch, the LTV response is monotonically increasing in the size of the interest jump, from 0.7pp at the lowest notch to 3.7pp at the highest notch. Given the notches are at least 5pp apart, the estimated LTV responses are consistent with the assumption (made in the theoretical model) that bunchers move only one notch down.

Panel B of the table turns the reduced-form evidence into elasticities using the simple structural model from Section 3. The EIS $\sigma$ is based on the estimating indifference equation shown in Proposition 1, and the reduced-form borrowing elasticity $\varepsilon$ is based on the equation on shown in Proposition 2. Besides the bunching moments, the estimation of elasticities requires us to set a few additional parameters that are not directly observed: the discount factor $\delta$, future income $y_{1}$, and house price growth net of depreciation $\Pi_{1}=(1-d) \frac{P_{1}}{P_{0}}$. As discussed in detail in the previous section, the estimation is not sensitive to the assumptions we make about these parameters. ${ }^{34}$ Arguably, the crudest assumption in this exercise is the two-period nature of the model, but we have repeated the exercise for a multi-period version of the model and the EIS estimates are virtually identical (the multi-period extension is presented in appendix C). ${ }^{35}$

As shown in the table, the EIS is small. It ranges from 0.03 to 0.18 across the different notches, and the average elasticity obtained from the pooled notch is close to 0.1 . The pooled estimate is very close to the calibrated EIS obtained from the global simulation exercise in the previous section. Translating the structural EIS estimates into reduced-form borrowing elasticities, we obtain stable values of $\varepsilon$ across the different notches, all in the neighborhood of 0.5 . As implied by the result in Proposition 2, when $\sigma$ converges to zero, the value of $\varepsilon$ converges to $R /(1+R) \simeq 0.5$ and represents a pure wealth effect. Given the low values of the EIS deriving from our structural model, most of the borrowing response to interest rates is due to the wealth effect. ${ }^{36}$

The elasticity estimates in Table 2 are corrected for optimization frictions using the Kleven-

\footnotetext{
${ }^{34}$ We assume that the annual discount factor equals $\delta=0.96$, that future income equals current income $\left(y_{1}=y_{0}\right)$, and that annual house price growth equals its historical average in the UK $\left(P_{1} / P_{0}=1.026\right)$ net of a depreciation rate taken from the literature $(d=0.025)$. The period length is set equal to 3.34 years, corresponding to the average time between refinance events in the data.

${ }^{35}$ While the structural EIS is not sensitive to the number of periods, the reduced-form borrowing elasticity does change when changing the number of periods (all else being equal). Adding periods to the model tends to lower the reducedform elasticity by lowering (spreading out) the wealth effect of the interest rate.

${ }^{36}$ Table A.1 shows these estimates obtained using the selection-corrected equity extraction predictions described in Section 2.4 to form the counterfactual distribution shown in Figure A.4. The results are extremely similar.
} 
Waseem adjustment factor $a$, i.e. the fraction of borrowers located in the dominated regions above notches who do not move. The calculation of the dominated regions was based on the average interest jumps at notches in an empirical setting that feature heterogeneity in the size of interest jumps across banks and products. In particular, because some banks do not feature certain notches during certain time periods, it is conceivable that the mass immediately above notches disproportionately comes from such no-notch contracts. In this case we would overstate the amount of friction, and therefore overstate the EIS. ${ }^{37}$ There are other reasons why the Kleven-Waseem friction adjustment could be biased (see Kleven 2016). To investigate the sensitivity to these issues, Table 3 puts bounds on the friction adjustment and the EIS by considering the following scenarios: (i) no friction adjustment (lower bound on the EIS); (ii) a friction adjustment based on the dominated region and notched banks only; (iii) a friction adjustment based on the dominated region and all banks (our baseline estimates); (iv) a friction adjustment assuming that all mass in the hole (not only the dominated region) is due to friction (upper bound on the EIS). The table shows that the EIS estimates are relatively tight. Even under the extreme assumption that all mass in the hole is due to friction, the average EIS is fairly modest at around 0.3. ${ }^{38}$

The results in Table 2 are estimates of the average EIS in the population, but there may be subgroups with a higher EIS. In fact, an important advantage of our rich data is the ability to study heterogeneity in the EIS across subsamples. Hence, in Table 4 we explore heterogeneity in the EIS along a number of dimensions. For each covariate, we partition the sample into 4 quartiles and separately estimate the EIS in each quartile. The table reveals only modest heterogeneity in the EIS. The elasticity is larger for older households, those with lower income, those with higher loan-to-income ratios, and those experiencing the fastest house-price growth. ${ }^{39}$ However, the differences are only modest, with the EIS ranging from 0.02 to only 0.15 across all the subgroups considered.

To conclude, we have translated bunching at mortgage notches into structural EIS parameters through the lens of the simplest possible dynamic model. In this model, the only way households

\footnotetext{
${ }^{37}$ However, the potential bias is limited by the fact that the fraction of no-notch contracts is very small as we saw in Figure A.9.

${ }^{38}$ This same number is also equal to the upper bound on the EIS in the sample, so that we can bound the EIS between 0 and 0.3 if households are heterogeneous in this parameter. If we assume that the EIS is heterogeneous in the population, as in (9) above, the largest EIS is that of the buncher forgoing the largest amount of debt. This is estimated from the location where the counterfactual and the actual LTV distributions meet to the right of the notch, which is equivalent to assuming that all households present in the "hole" are subject to optimization frictions.

The upper bound is estimated from the

${ }^{39}$ This analysis considers each dimension of heterogeneity in isolation, raising the concern that if the covariates are correlated, it is unclear which covariate to attribute the heterogeneity to. To address this, in results available from the authors, we split the data at the median of age, income, and loan-to-income ratio, calculated the EIS separately in these 8 subgroups, and then regressed the estimated EIS on the three covariates. The results confirm the patterns in Table 4.
} 
can reallocate consumption over time is through borrowing against their house. This implies that bunching at mortgage notches maps directly into intertemporal consumption reallocation and therefore reveal the EIS. By assuming that households can bunch only by reducing current consumption, as opposed to drawing down liquid assets, we are estimating an upper bound on the EIS. The presence of liquid assets gives households an extra margin of adjustment and will in general add to bunching, unless liquidity demand is completely inelastic to interest rates. ${ }^{40}$ That is, a given amount of observed bunching is consistent with a smaller consumption reallocation in the presence of liquidity/portfolio effects, and by implication a smaller value of the EIS. This makes our small EIS estimates very informative.

As implied by this discussion, exactly identifying the EIS requires a model of how liquidity demand responds to the interest rate. This calls for a model that allows for uncertainty and a precautionary savings motive, in which case the responsiveness of liquidity depends on the amount of uncertainty and risk preferences. In our baseline model with CRRA preferences, the coefficient of relative risk aversion is the inverse of the EIS, and so a low EIS will make households very risk averse and therefore make liquidity demand inelastic. To allow for more flexibility in liquidity responses, it is natural to separate the EIS and risk aversion preferences using Epstein-Zin preferences. In the following section, we develop a stochastic lifecycle model that allows for all of these features in order to demonstrate how the EIS relates to bunching in a richer and more realistic setting. However, for the high-level reasons discussed here, the liquidity channel does not give rise to larger estimates of the EIS, all else equal. ${ }^{41}$

\section{Estimating the EIS: Full Structural Model}

\subsection{Model}

We now turn to estimating the EIS in our extended structural model. Households live for $T$ periods (years) and choose consumption, housing, liquidity, mortgage debt, and bequests. Future house prices and income are uncertain. The mortgage interest rate is a step function of LTV, corresponding to the notched interest schedule in the UK. Households may buy and sell housing, and they may hold an additional liquid asset. As noted above, liquidity demand may be confounded with con-

\footnotetext{
${ }^{40}$ Adding fixed (price inelastic) liquid wealth to our model would have no impact on our results, because in that case borrowers still bunch using only consumption.

${ }^{41}$ When moving to the full structural model below, we generalize in more dimensions than the liquidity channel. Due to the combination of generalizations, it is possible for the full structural estimates to be larger than the baseline estimates presented above.
} 
sumption demand in driving bunching behavior. The presence of a liquid asset in the model allows a quantitative assessment of the relative importance of these two channels in driving bunching. We present the basic structure of the model here and relegate its full analysis to Appendix D.

SETUP: Households have preferences over non-durable consumption $c_{t}$ and housing services $H_{t}$, defined recursively as

$$
V_{t}=\left(\left(c_{t}^{\alpha} H_{t+1}^{1-\alpha}\right)^{\frac{\sigma-1}{\sigma}}+\delta\left(E_{t}\left\{V_{t+1}^{1-\gamma}\right\}\right)^{\frac{1}{1-\gamma} \frac{\sigma-1}{\sigma}}\right)^{\frac{\sigma}{\sigma-1}}
$$

where $V_{t}$ is the net present value of utility at period $t, \sigma$ is the EIS, $\gamma$ is the coefficient of relative risk aversion, and $\alpha$ is the share of housing in overall consumption. These preferences follow Epstein \& Zin (1989) and Weil (1990) and allow for a distinction between risk aversion and the EIS. This helps ensure that our EIS estimates are not influenced by the dual role this parameter plays in standard CRRA preferences. The unit elasticity of substitution between housing and non-housing consumption (Cobb-Douglas) is justified by the observation that expenditures on housing services have historically been a constant share of total household expenditures (see e.g., Piazzesi \& Schneider 2016).

Households value end-of life wealth $W_{T+1}$ via a reduced-form bequest motive, i.e.

$$
V_{T+1}=\Gamma W_{T+1}
$$

where $\Gamma$ is a parameter governing the intensity of bequest motives.

Households enter period $t$ with two assets and one liability. The assets are housing $H_{t}$ with a market price of $P_{t}$, and a liquid asset $L_{t}$ denominated in units of the numeraire consumption good. The liability is mortgage debt $D_{t}$, again denominated in units of the consumption good. The real gross mortgage interest rate is given by $R_{t}=1+r_{t}$, while the liquid asset obtains zero nominal return. For simplicity, we abstract from short-term credit so that households' liquidity constraint is given by $L_{t} \geq 0$.

To conserve on computational power, we assume that housing quality $H_{t}$ can take on three values normalized to $\{1,1.2,1.4\}$. This is sufficient to allow for a lifecycle pattern featuring increasing housing in the beginning of life and decreasing housing at the end of life. With this discrete grid, moving costs turn out to be relatively unimportant. Our initial simulation exercises showed that moving costs occasionally delay moving by a year or two, but do not change the qualitative lifecycle pattern. We therefore abstract from the moving cost in what follows. 
Mortgage contracts have fixed maturities of $m$ years, after which a penalizing reset interest rate kicks in. We assume this reset rate is sufficiently high that households never refinance after this point. Households also face an early repayment penalty if they choose to refinance before the mortgage matures. Penalties equal to $5-10 \%$ of the outstanding loan are common in the UK. Simulating the model with penalties of this magnitude shows that households virtually never refinance early. Accordingly, we assume that households refinance after $m$ years unless they move (in which case the prepayment penalty waved as is typically the case in the UK). We assume a simple amortization schedule with constant annual repayments ensuring full repayment by age 70 (The typical mortgage contract in the UK requires full repayment before the borrower reaches the age of 70.) That is, the amortization rate is given by

$$
\mu_{t}=\frac{1}{70-A g e+1} .
$$

Of course, households have ample opportunities to readjust amortization by repaying or extracting equity when refinancing. We set the terminal period to $T=70$. This understates average longevity in the UK, but households are typically inactive in the mortgage market after this age. We may think of the bequest function $V_{T+1}$ as capturing the overall preference for wealth at age 70 combining retirement and bequest motives.

When a household refinances, it must pay a fixed mortgage origination fee of $\Omega$ consumption units. Houses depreciate in quality at a rate $d$ in each period. For simplicity, we assume that households maintain their houses in each period so as to replace its depreciated value, i.e. pay a maintenance fee of $d \cdot P_{t} H_{t}$ in period $t$. Households obtain an income stream of $y_{t}$ consumption units in period $t$.

With these features, the household's budget constraint is given by

$$
\begin{aligned}
c_{t} & =y_{t}+\left(1-\pi_{t}\right) L_{t}-L_{t+1} \\
& +P_{t}\left((1-d) H_{t}-H_{t+1}\right) \\
& +D_{t+1}-R_{t} D_{t}-\Omega I_{t}^{\mathrm{R}},
\end{aligned}
$$

where $I_{t}^{R}$ is an indicator equal to 1 if the household refinances $\left(D_{t+1} \neq\left(1-\mu_{t}\right) D_{t}\right)$, and $\pi_{t}$ gives the inflation rate for non-housing consumption.

The interest rate is a spread over a risk-free base rate. The spread is a function of LTV, corresponding to the notched mortgage interest schedule in the UK. Formally, $R_{t}=R_{t}^{0}+\rho\left(\lambda_{s}\right)$ where $R_{t}^{0}$ is the base rate and where the spread $\rho($.$) is a step function of the LTV ratio \lambda_{s}$ at the time of 
mortgage origination $s$. The LTV ratio is defined as $\lambda_{s} \equiv \frac{D_{s+1}}{P_{s} H_{s+1}}$.

Households have rational expectations, are forward looking, and optimize in each period subject to the aforementioned adjustment costs. This may seem at odds with our assessment that a significant fraction of households face optimization frictions (reflected in our estimates of $a$ in Tables 2-3). However, in our empirical estimation of the model, we will use bunching moments adjusted for optimization frictions, as outlined in Section 3. We can therefore restrict attention to fully optimizing agents, as these moments reflect the amount of bunching that would prevail if households faced no optimization frictions. This has the advantage that we do not have to take a position on the exact form of optimization frictions facing households in our theoretical framework.

The model is solved computationally, with the full details on our approach being described in Appendix D. We solve for the value of the EIS using the bunching moments along with an indifference equation similar to (8), but using the value functions arising from the extended model. Parameter values other than the EIS are calibrated to match features of the data or taken from the existing literature. The calibration is summarized in Table A.2 in the appendix.

\subsection{Results}

Table 5 shows EIS estimates resulting from the extended model. Standard errors are obtained by block bootstrapping with replacement. The first rows of the table restate our estimates of bunching $b$, the fraction of non-optimizers $a$, bunching adjusted for optimization friction $b_{A d j}=\frac{b}{1-a}$, and the implied LTV response for optimizers $\Delta \lambda_{A d j}$. We report these estimates at each individual notch as well as at an "average" notch. The latter is obtained as a weighted average of the estimates at individual notches, with weights proportional to the number of borrowers around each notch in the counterfactual distribution. ${ }^{42}$

In the last row of Table 5, we report our estimates of the EIS $\sigma$ at each notch. The EIS is small and stable across notches, except at the 85\% LTV notch where the elasticity is somewhat larger. The average EIS is slightly below 0.1. This is essentially identical to the estimate deriving from the simple two-period model shown in Table 2, despite all the bells and whistles of the full structural model. This suggests that the low EIS estimates reported earlier are not driven by the simplifying assumptions of the 2-period model, but rather by the magnitude of bunching observed in the data. ${ }^{43}$

\footnotetext{
${ }^{42}$ When using the full structural model, we cannot estimate the EIS at a pooled notch like we did in Section 4 . In the simple model, we considered a single refinancing episode in which borrowers made bunching decisions around a single notch. In the extended model, we consider a setting with repeated refinancing episodes in which borrowers make bunching decisions at time $t$ anticipating the full menu of five notches in future refinancing episodes.

${ }^{43}$ Why does the $85 \%$ notch yield a larger EIS? Our model implies substantial equity injection at the counterfactual at
} 
It also confirms the identification arguments made in section 3.3.

Why does model specification matter so little? Despite the greater complexity of the model developed here compared to the two-period model in Section 3, solving for the EIS ultimately boils down to a similar indifference equation. There are two main differences between the models. First, the continuation value in the two-period model is simply the utility of second-period consumption, as opposed to the much more involved continuation value $V_{t+1}$ in the full lifecycle model. This has little quantitative implication for EIS estimates. This is because most factors that affect the continuation value affect it by similar magnitudes when bunching at the notch and when locating in the interior, and therefore roughly cancel out from the two sides of the indifference equation (8). Rather, it is the curvature of the continuation value with respect to debt that governs bunching motivations and therefore EIS estimates. But the curvature of the value function $V_{t}$ with respect to wealth (and therefore debt) is approximately equal to the EIS, as is often the case in dynamic consumption models. Hence the bunching decision is roughly the same in the full model as it was in the two-period model.

Second, our full structural model allows for a liquid asset and for liquidity choice, while no liquid asset was available in the two-period model. This is a more substantive difference, because the liquid asset gives households an additional margin of adjustment when making the bunching decision. With liquid assets, households confronting the bunching decision can now forgo either consumption or liquidity to lower their LTV to the notch. In equilibrium, households equalize the marginal value of consumption with the marginal value of liquidity, so it is optimal to forgo a combination of the two. The moderate responses to interest rates implied by the observed bunching suggest that households are inelastic in their demand for consumption and liquidity. With reasonable values of risk aversion and uncertainty - the main parameters governing liquidity demand - the liquidity margin facilitates bunching, which heightens the "puzzle" of households' small responses to borrowing rates. In contrast, the simple model without liquidity is equivalent to a model with a binding liquidity constraint or one with perfectly inelastic liquidity demand. Hence, the model with liquidity should give smaller EIS estimates all else equal. However, because the EIS estimates from the baseline model were already small, incorporating liquidity choice has only a small

the time of bunching for the average household at this notch. This means that households are short of liquidity when attempting to bunch at the $85 \%$ notch and must forgo some current consumption for capital repayment even at the counterfactual. This makes bunching at the $85 \%$ notch particularly painful and justifies the small amount of bunching observed in the data even at a higher EIS approaching 0.3. This result illustrates how our model incorporates liquidity constraints in its estimation, but also that the EIS remains low even when incorporating severe liquidity constraints. We do not observe households' wealth directly, but if households at this notch have more wealth than our model suggests, our estimated EIS is overstated. 
impact on the estimation.

We have shown that our EIS estimates are largely robust to first-order changes in modeling assumptions, i.e. moving from a very simplified 2-period model to a full dynamic lifecycle model. In this section we subject our model to an additional battery of tests to explore its robustness to specification and parameter values. Table 6 shows EIS estimates (at the average notch) across a range of parameterizations. In each row, the estimate in boldface corresponds to the baseline assumption considered above.

We start by exploring robustness to household impatience. The first row shows robustness to the discount factor $\delta$, while the second row allows for hyperbolic discounting and varies the coefficient of present bias $\beta .^{44}$ As noted earlier, the discount factor (or present bias) largely governs the level of borrowing, while the EIS governs the responsiveness of borrowing to interest rates. As a result, changes in the discount factor $\delta$ or the present bias factor $\beta$ have relatively little impact on the estimated EIS. Even under extreme present bias $(\beta=0.3)$, the EIS estimate is only moderately larger than in the baseline.

We next turn to risk aversion, which governs liquidity preferences and may affect EIS estimates. We explore values of $\gamma$ ranging from risk neutrality $(\gamma=1)$ to high levels of risk aversion. The last column shows the CRRA case $\gamma=\frac{1}{\sigma}$, which implies extreme risk aversion due to the low range of $\sigma$ in our estimates. Despite the potential role of liquidity in affecting our estimates, the EIS remains relatively small for the entire range of risk preferences.

The remaining robustness checks alter household expectations along a number of dimensions. First, we alter interest rate expectations. The baseline interest rate process was calibrated from the UK yield curve, which currently reflects expectations of interest rates near zero for an extended period. We see that our EIS estimates are similar if households expect higher interest rates (shifting the yield curve upwards by 1pp, 2pp, and 3pp). Second, we see that the estimated EIS is insensitive to expectations of (mean) house price growth and not particularly sensitive to uncertainty about house prices. We alter the expected lifecycle profile of income from static income expectations to a trajectory implying real income growth at 7\% per annum. Again, the implications for the estimated EIS are small. Finally, we alter income uncertainty by either changing the probability of unemployment or altering the replacement rate for unemployed workers. In both cases, the EIS remains moderate.

\footnotetext{
${ }^{44}$ For this latter exercise, we alter the model so that households maximize the following function in each period

$$
\left(\left(c_{t}^{\alpha} H_{t+1}^{1-\alpha}\right)^{\frac{\sigma-1}{\sigma}}+\beta \delta\left(E_{t}\left\{V_{t+1}^{1-\gamma}\right\}\right)^{\frac{1}{1-\gamma} \frac{\sigma-1}{\sigma}}\right)^{\frac{\sigma}{\sigma-1}}
$$
}

with $V_{t+1}$ defined as before. 
The message emerging from these robustness checks is that our EIS estimates are insensitive to the parametric assumptions of the model. This confirms the conceptual arguments made earlier that bunching identifies the EIS, because other parameters in general have minor impacts on bunching. It also confirms the simulation exercises in section 3.3 suggesting that the raw data necessitates a low EIS, because higher values (such as log preferences) would generate a radically different LTV distribution.

Finally, we note that a low elasticity of intertemporal substitution could be explained by other behavioral models and frictions than those considered here. For example, Campbell \& Cochrane (1999) show that consumption habits may lead to low elasticities of intertemporal substitution. Chetty \& Szeidl (2016) show that consumption commitments (captured by adjustment costs in consumption) may generate similar behaviors as consumption habits. Such models offer potential mechanisms that could explain the low values of the EIS we find. ${ }^{45}$

\section{Conclusion}

A large literature estimates the elasticity of intertemporal substitution using non-experimental data and structural models. The EIS is arguably one of the most important parameters in economics as it plays a central role in almost any economic model involving intertemporal choice. It governs consumption and savings responses to interest rate changes, affects the reaction of consumption to income shocks, is an important parameter for asset pricing, and provides a key statistic for evaluating a range of macroeconomic and microeconomic policies. We contribute to efforts to estimate the EIS with a new approach that combines quasi-experimental identification with structural methods.

Our new methodology translates empirical moments arising from bunching at mortgage interest notches into EIS estimates. Using administrative mortgage data from the UK, we first illustrate our approach in a simple two-period model, and then generalize to a rich stochastic lifecycle model. The two models produce very similar results: the EIS is small, around 0.1. Although we observe lots of bunching at notches, the intertemporal incentives created by those notches are so large that there would have to be much more bunching to justify large values of the EIS. Our results are close to the level obtained in the early macro-based literature (e.g. Hall 1988), although we have arrived at this conclusion using a fundamentally different approach.

\footnotetext{
${ }^{45}$ However, note that non-responses due to consumption commitments may be partly captured by the Kleven-Waseem friction adjustment approach.
} 


\section{References}

Attanasio, Orazio, Bottazzi, Renata, Low, Hamish, Nesheim, Lars, \& Wakefield, Matthew. 2012. Modelling the Demand for Housing over the Lifecycle. Review of Economic Dynamics, 15(1), 1-18. 75

Attanasio, Orazio P., \& Weber, Guglielmo. 1993. Consumption Growth, the Interest Rate and Aggregation. Review of Economic Studies, 60(3), 631-649. 3

Attanasio, Orazio P., \& Weber, Guglielmo. 1995. Is Consumption Growth Consistent with Intertemporal Optimization? Evidence from the Consumer Expenditure Survey. Journal of Political Economy, 103(6), 1121-1157. 3

Attanasio, Orazio P., \& Weber, Guglielmo. 2010. Consumption and Saving: Models of Intertemporal Allocation and Their Implications for Public Policy. Journal of Economic Literature, 48, 693-751. 3

CAmpbell, John, \& Cochrane, John. 1999. By Force of Habit: A Consumption-Based Explanation of Aggregate Stock Market Behavior. Journal of Political Economy, 107(2), 205-251. 32

Campbell, John Y., \& MankiW, N. Gregory. 1989. The Response of Consumption to Income: A Cross-Country Investigation. European Economic Review, 35(4), 723-756. 3

Chetty, Raj, \& Szeidl, AdAm. 2016. Consumption Commitments and Habit Formation. Econometrica, 84(2), 855-890. 32

Chetty, Raj, Friedman, John N., Olsen, Tore, \& Pistaferri, Luigi. 2010. Adjustment Costs, Firm Responses, and Labor Supply Elasticities: Evidence from Danish Tax Records. NBER Working Paper 15617. 4

Chetty, Raj, Friedman, John N., Olsen, TOre, \& Pistaferri, Luigi. 2011. Adjustment Costs, Firm Responses, and Micro vs. Macro Labor Supply Elasticities: Evidence from Danish Tax Records. Quarterly Journal of Economics, 126(2), 749-804. 2, 4, 10

DeFusco, Anthony, \& Paciorek, Andrew. 2017. The Interest Rate Elasticity of Mortgage Demand: Evidence From Bunching at the Conforming Loan Limit. American Economic Journal: Economic Policy, 9, 210-240. 3 
Dunsky, Robert M., \& Follain, James R. 2000. Tax-Induced Portfolio Reshuffling: The Case of the Mortgage Interest Deduction. Real Estate Economics, 28, 683-718. 3

EinaV, LiRAN, Finkelstein, Amy, \& Schrimpf, PAUl. 2015. The Response of Drug Expenditure to Non-Linear Contract Design: Evidence from Medicare Part D. Quarterly Journal of Economics, 130, 841-899. 2, 4

EinaV, Liran, Finkelstein, Amy, \& Schrimpf, PAul. 2017. Bunching at the Kink: Implications for Spending Responses to Health Insurance Contracts. Journal of Public Economics, forthcoming. 2,4

Epstein, Larry G., \& Zin, Stanley E. 1989. Substitution, Risk Aversion, and the Temporal Behavior of Consumption and Asset Returns: A Theoretical Framework. Econometrica, 57(4), 937969. 27

Evans, Owen J. 1983. Tax Policy, the Interest Elasticity of Saving, and Capital Accumulation: Numerical Analysis of Theoretical Models. American Economic Review, 73(3), 398-410. 4

Flavin, Marjorie A. 2012. Housing, Adjustment Costs, and Macro Dynamics †. CESifo Economic Studies, 58(3), 471-494. 73

Follain, JAMES R., \& DunSKy, Robert M. 1997. The Demand for Mortgage Debt and the Income Tax. Journal of Housing Research, 8(2), 155-199. 3

Gelber, Alexander M., Jones, Damon, \& Sacks, DAniel W. 2017. Estimating Earnings Adjustment Frictions: Method and Evidence from the Social Security Earnings Test. Working Paper, March 2017. 4

Gruber, JonAthan. 2013. A Tax-Based Estimate of the Elasticity of Intertemporal Substitution. Quarterly Journal of Finance, 3(1), 1-20. 3

HAll, Robert E. 1988. Intertemporal Substitution in Consumption. Journal of Political Economy, 96(2), 339-357. 3, 32

Harding, John P., Rosenthal, Stuart S., \& Sirmans, C.F. 2007. Depreciation of housing capital, maintenance, and house price inflation: Estimates from a repeat sales model. Journal of Urban Economics, 61(2), 193 - 217. 62, 75 
HAVRÁNEK, TOMÁš. 2015. Measuring Intertemporal Substitution: The Importance Of Method Choices And Selective Reporting. Journal of the European Economic Association, 13(6), 1180-1204. 3

HecKman, JAMES. 1979. Sample Selection Bias as a Specification Error. Econometrica, 47, 153-161. 11

Jappelli, Tullio, \& Pistaferri, Luigi. 2007. Do People Respond to Tax Incentives? An Analysis of the Italian Reform to the Deductibility of Home Mortgage Interests. European Economic Review, 51, 247-271. 3

Kaplan, Greg, \& Violante, Giovanni L. 2014. A Model of the Consumption Response to Fiscal Stimulus Payments. Econometrica, 82(4), 1199-1239. 69, 77

KLeVen, Henrik. 2016. Bunching. Annual Review of Economics, 8, 435-464. 2, 4, 5, 10, 12, 17, 25

KLeVen, Henrik JACOBSEN, \& WASEem, MAZHAR. 2013. Using Notches to Uncover Optimization Frictions and Structural Elasticities: Theory and Evidence from Pakistan. Quarterly Journal of Economics, 128(2), 669-723. 2, 3, 10, 14, 16, 17, 18

Ling, David C., \& McGill, Gary A. 1998. Evidence on the Demand for Mortgage Debt by Owner-Occupants. Journal of Urban Economics, 44, 391-414. 3

Martins, Nuno C., \& Villanueva, ERnesto. 2006. The Impact of Mortgage Interest Rate Subsidies on Household Borrowing. Journal of Public Economics, 90, 1601-1623. 3

PiAZZESI, MONIKA, \& SCHNEIDER, MARTIN. 2016. Housing and Macroeconomics. NBER Working Papers 22354. 27

SaeZ, EMmanuel. 1999. Do Taxpayers Bunch at Kink Points? NBER Working Paper 7366. 4

SAeZ, Emmanuel. 2010. Do Taxpayers Bunch at Kink Points? American Economic Journal: Economic Policy, 2(3), 180-212. 2

Summers, LAwrence H. 1981. Capital Taxation and Accumulation in a Life Cycle Growth Model. American Economic Review, 71(4), 533-544. 4

Vissing-Jørgensen, Annette. 2002. Limited Asset Market Participation and the Elasticity of Intertemporal Substitution. Journal of Political Economy, 110(4), 825-853. 3 
WeIL, PhILlippe. 1990. Nonexpected Utility in Macroeconomics. Quarterly Journal of Economics, 105(1), 29-42. 27

Zeldes, Stephen P. 1989. Consumption and Liquidity Constraints: An Empirical Investigation. Journal of Political Economy, 97(2), 305-346. 3 


\section{Figure 1: ObSERVED LTV Distribution AMONG UK REFINANCERS}

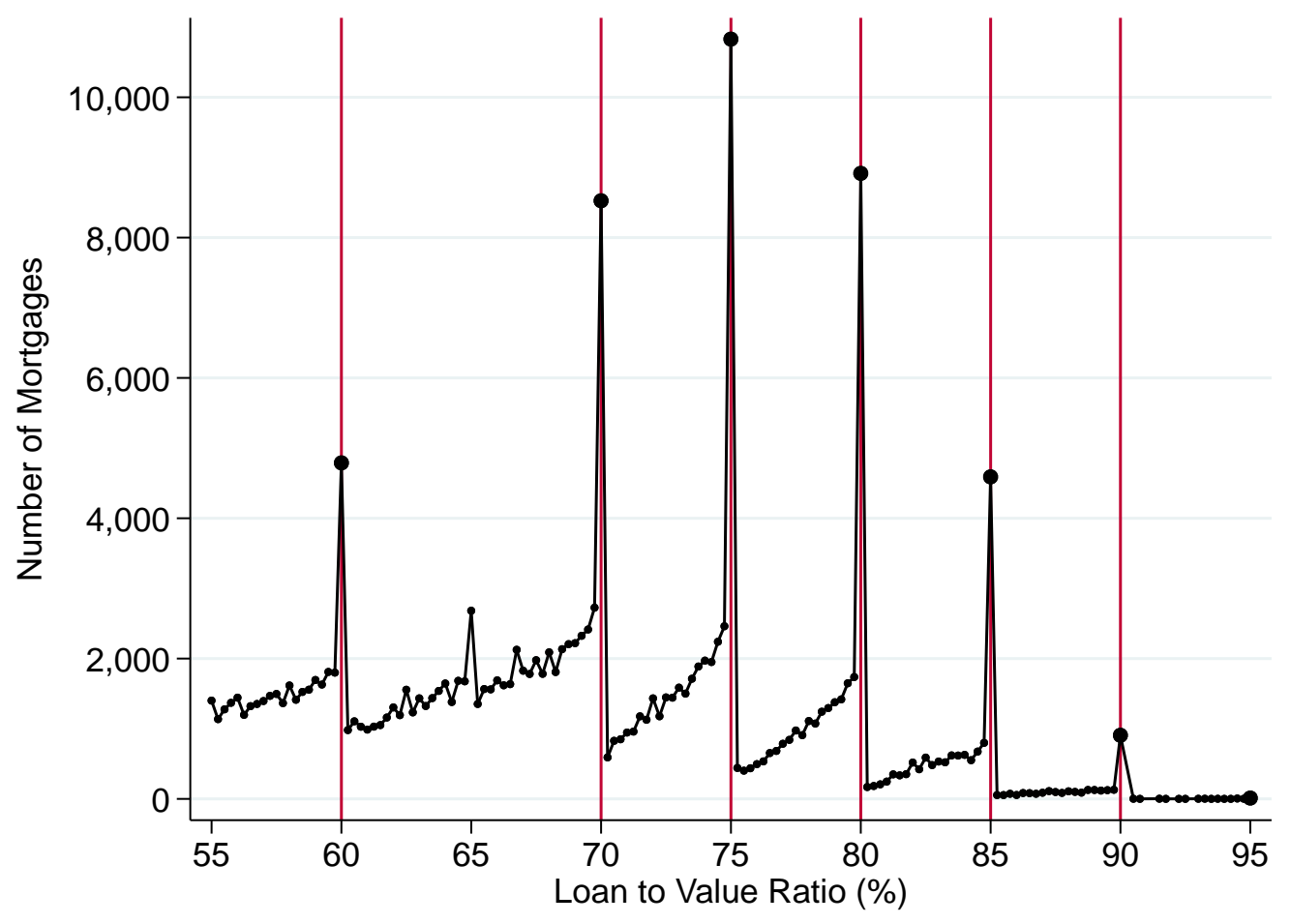

Notes: This figure shows the observed distribution of loan-to-value (LTV) ratios among refinancers in the UK between 2008-14. There are interest rate notches at LTV ratios of $60 \%, 70 \%, 75 \%, 80 \%, 85 \%$, and $90 \%$ (depicted by vertical lines). 
Figure 2: ObSERVED VS Simulated LTV Distributions UNDER AN EIS = 1

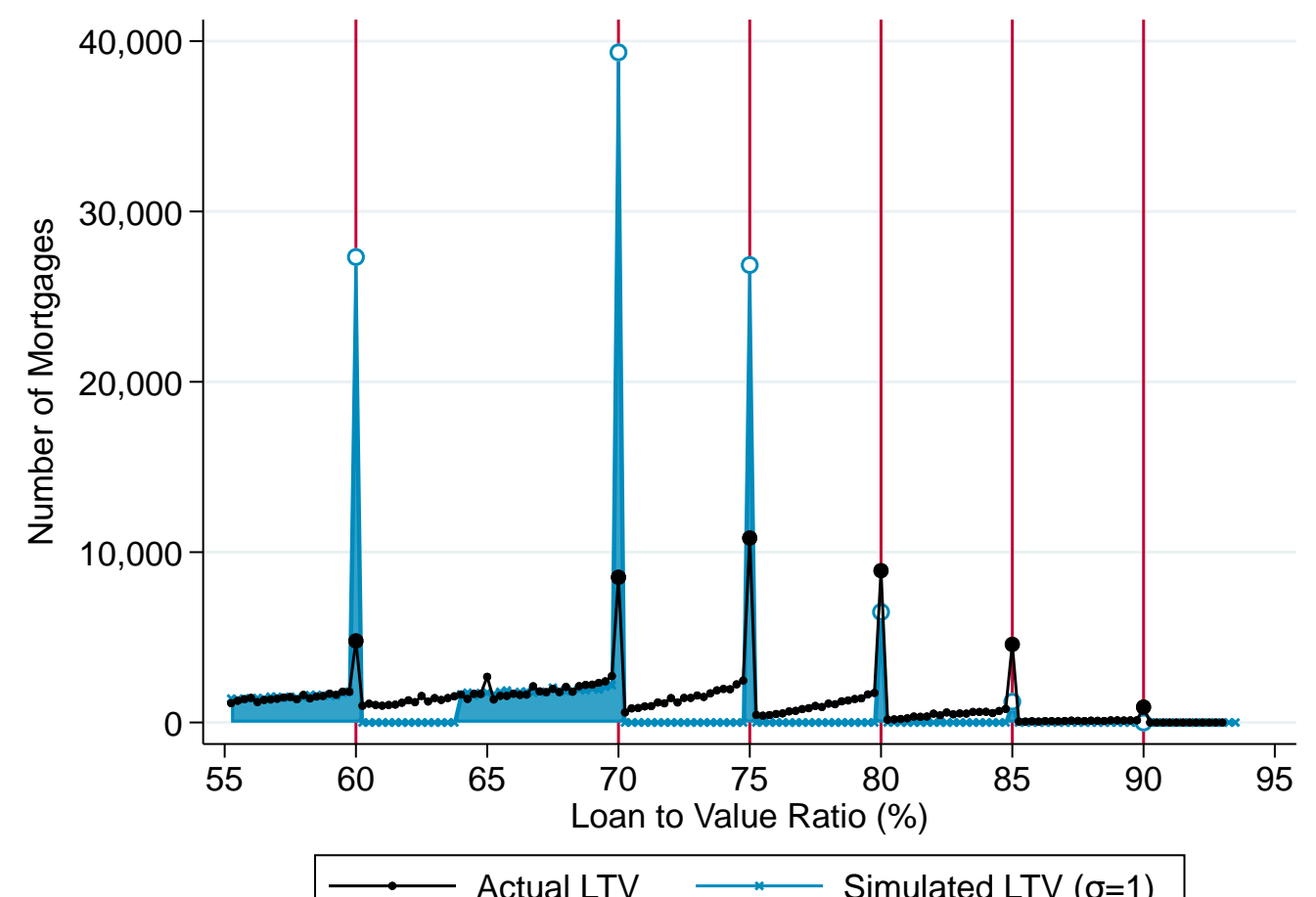

Notes: This figure compares the observed LTV distribution (black dots) to a simulated LTV distribution (blue solid) under Cobb-Douglas preferences $(E I S=1)$. The simulation is based on the standard lifecycle model introduced in Section 3 in which households choose their LTV optimally. Cobb-Douglass preferences are very far from being able to fit the data. 


\section{Figure 3: INTEREST RATE JUMPS AT NotcheS}

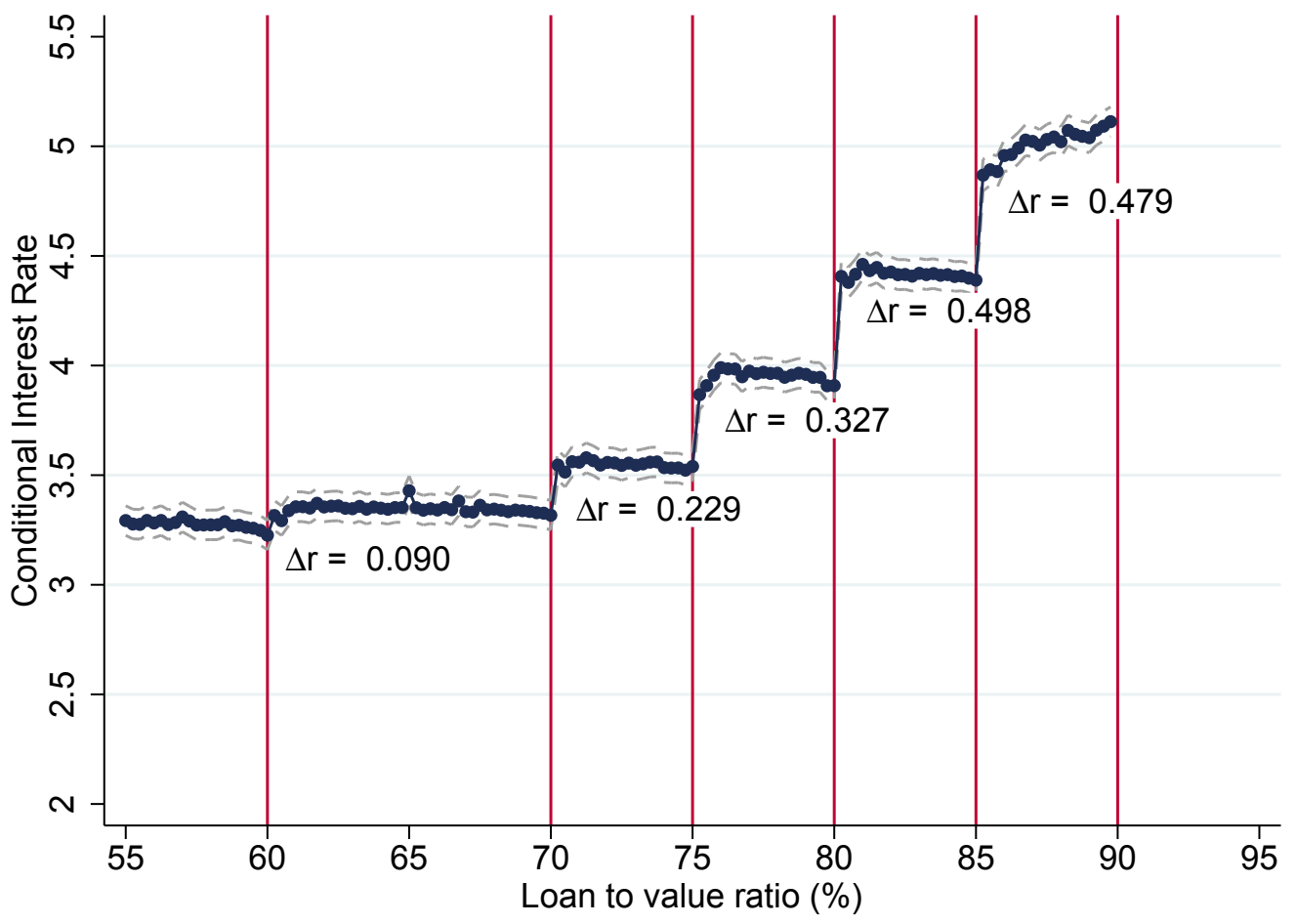

Notes: This figure shows the conditional interest rate as a function of the LTV ratio from the non-parametric regression (1). In each LTV bin, we plot the coefficient on the LTV bin dummy plus a constant given by the mean predicted value $E\left[\hat{r}_{i}\right]$ from all the other covariates (i.e., omitting the contribution of the LTV bin dummies). The figure shows that the mortgage interest rate evolves as a step function with sharp notches at LTV ratios of $60 \%, 70 \%, 75 \%$, $80 \%$, and $85 \%$. 


\section{Figure 4: Constructing the Counterfactual LTV Distribution}

\section{Panel A: Passive LTV Distribution}

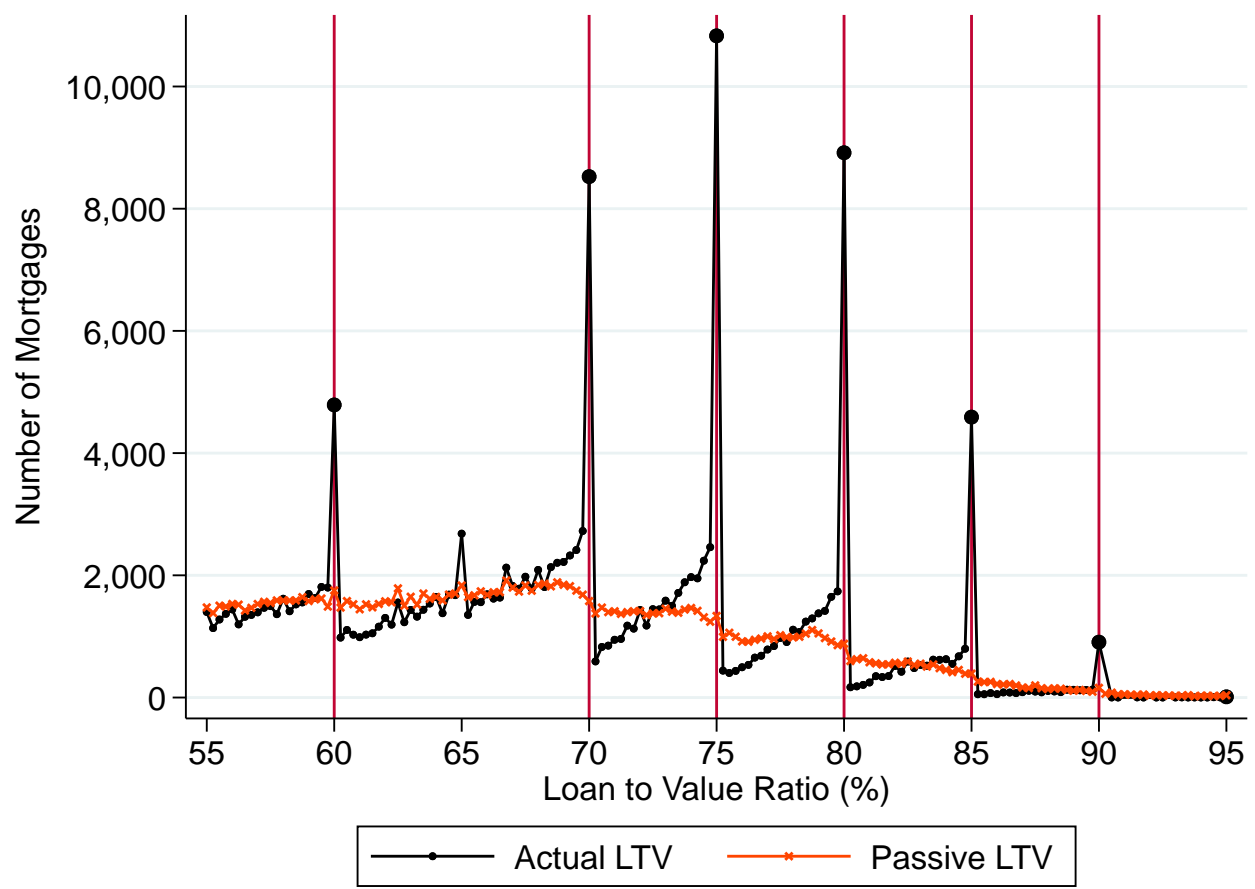

Panel B: Counterfactual LTV Distribution

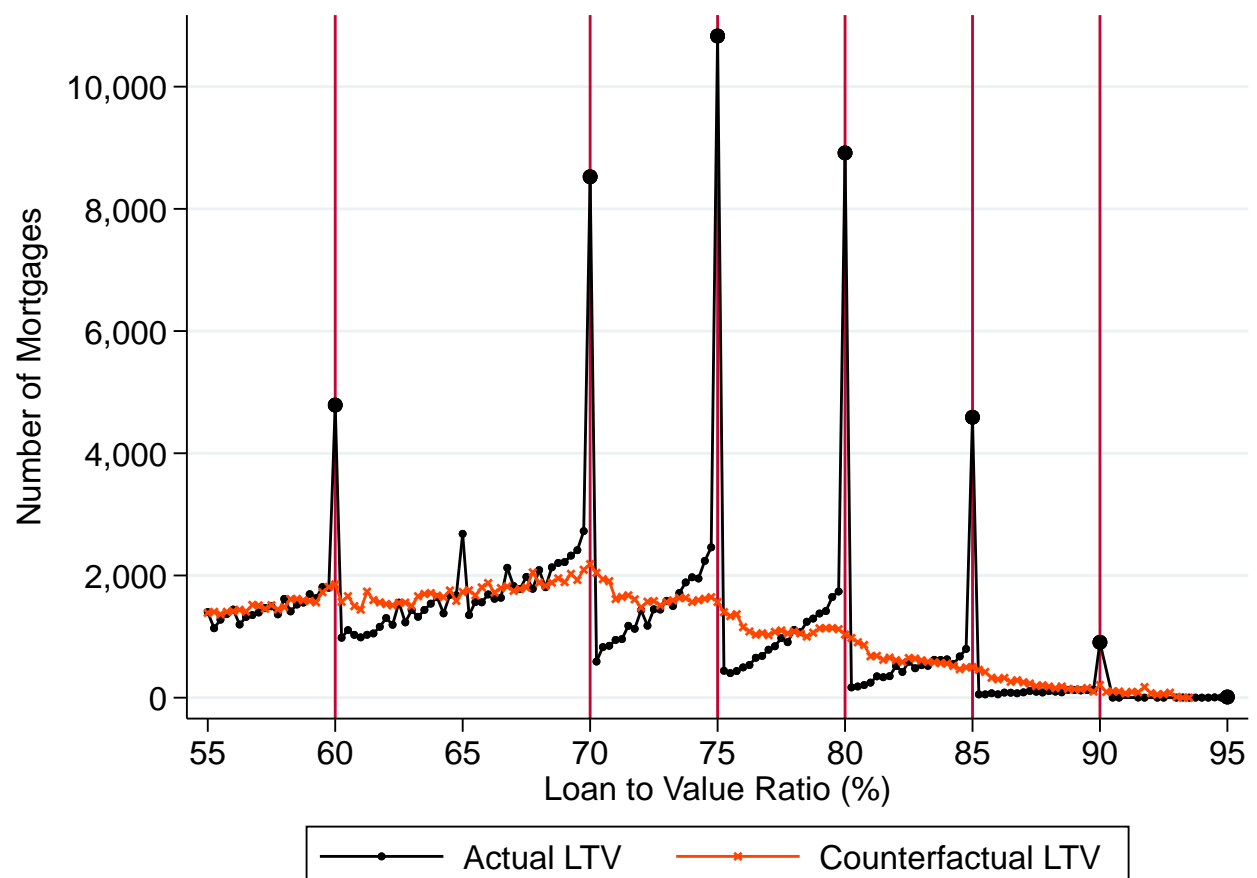

Notes: This figure shows the two steps in the construction of the counterfactual LTV distribution among refinancers. Each panel shows the actual LTV distribution in black dots (as in Figure 1). Panel A shows the distribution of passive LTVs in orange crosses, calculated based on the LTV of the previous mortgage, amortization, and the house value at the time of refinancing. Panel B shows the distribution of counterfactual LTVs in orange crosses, which adjusts passive LTVs for the average equity extraction of non-bunchers in the actual distribution. 


\section{Figure 5: BunChing in a Simple Model of INTERTEMPORAl Substitution}

\section{Panel A: The Marginal Bunching Household}

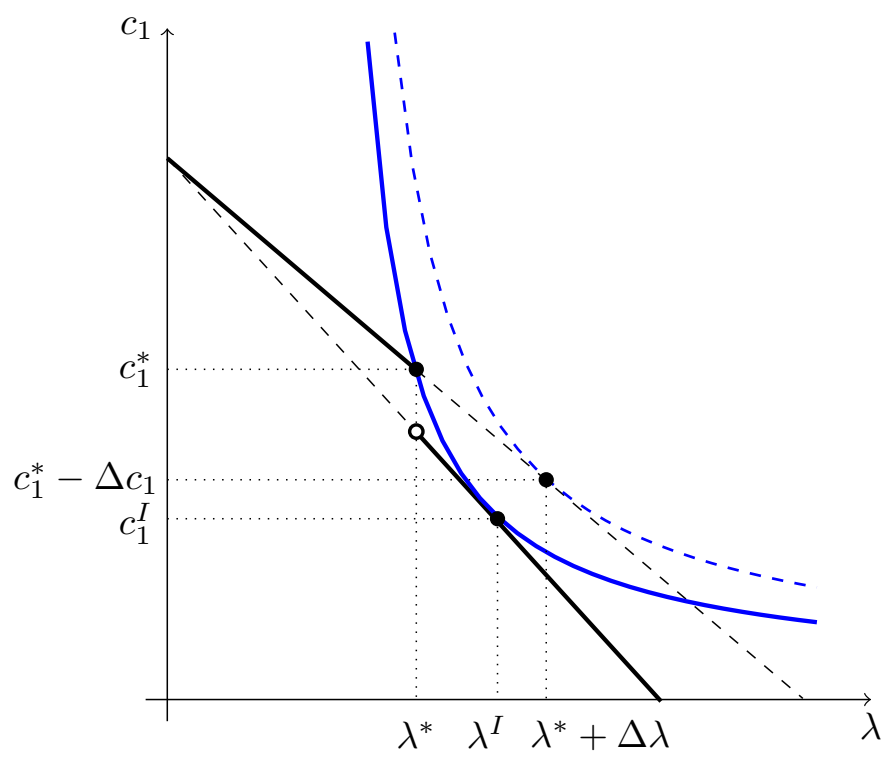

Panel B: LTV Density Distribution

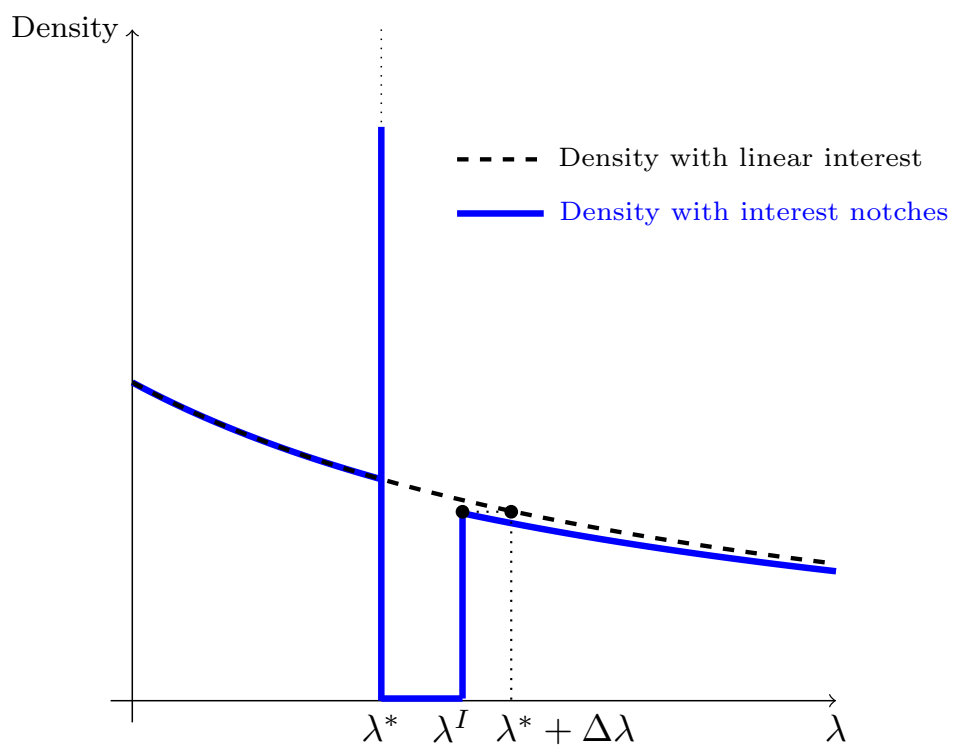

Notes: The figure shows the choice faced by a refinancing household faced with a notched interest rate schedule in a budget set diagram with LTV $\lambda$, on the horizontal axis and consumption in the future, $c_{1}$, on the vertical axis. Given the period zero budget constraint and the value of housing, an LTV choice $\lambda$ translates into current consumption $c_{0}$. The solid black line depicts the budget constraint with an interest notch at the LTV $\lambda^{*}$. The budget constraint has a slope $-R$ below $\lambda^{*}$ and a slope $-(R+\Delta R)$ above $\lambda^{*}$. There is a discrete jump in the budget set (rather than a kink) because the interest on the entire loan jumps discretely at the notch. The indifference curves shown are those of the marginal bunching household that is indifferent between bunching at the notch and borrowing $\lambda^{*}$, and a point $\lambda^{I}$ in the interior of the higher interest rate bracket. This household would have chosen a point $\lambda^{*}+\Delta \lambda$ in the absence of the interest rate notch. As described in Section 3, the optimality conditions for $\lambda^{I}$ and $\lambda^{*}+\Delta \lambda$ together with the household's indifference between $\lambda^{I}$ and $\lambda^{*}$ identify the curvature of the indifference curves—-the Elasticity of Intertemporal Substitution (EIS)—in terms of observable and/or estimable quantities. 


\section{Figure 6: ObSERVED VS Simulated LTV Distributions When VARYing THE EIS}

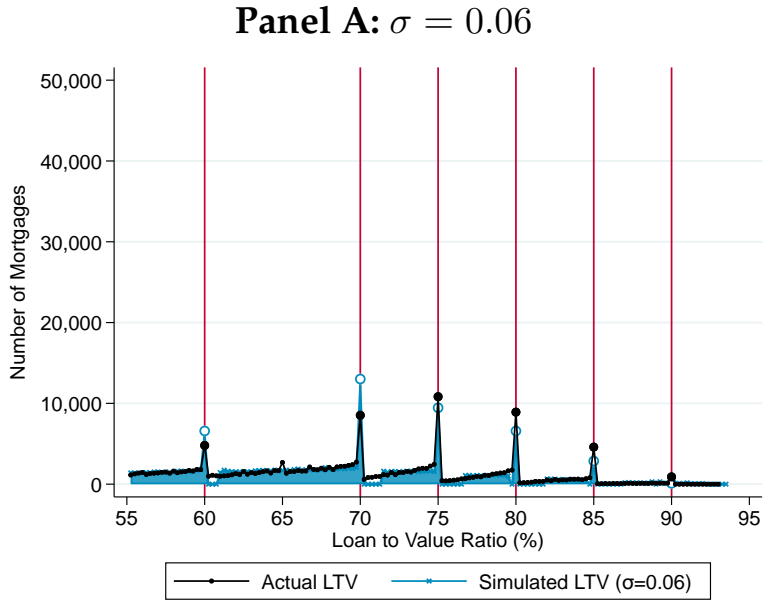

Panel C: $\sigma=1$

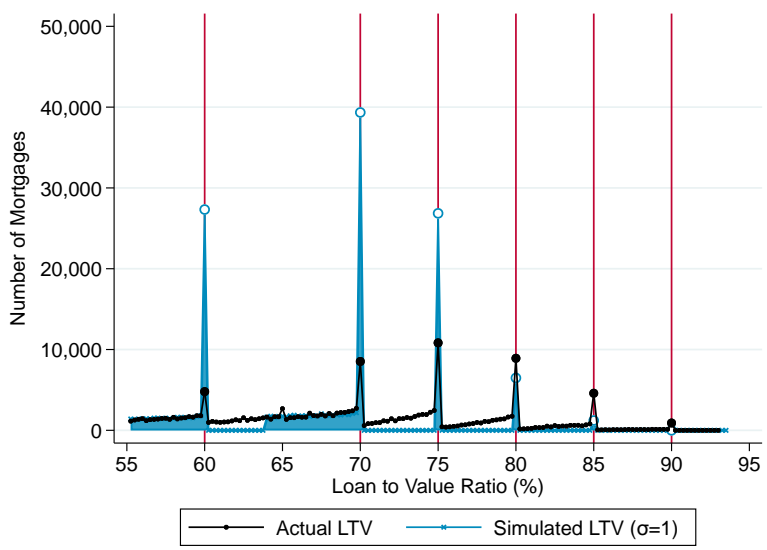

Panel B: $\sigma=0.5$

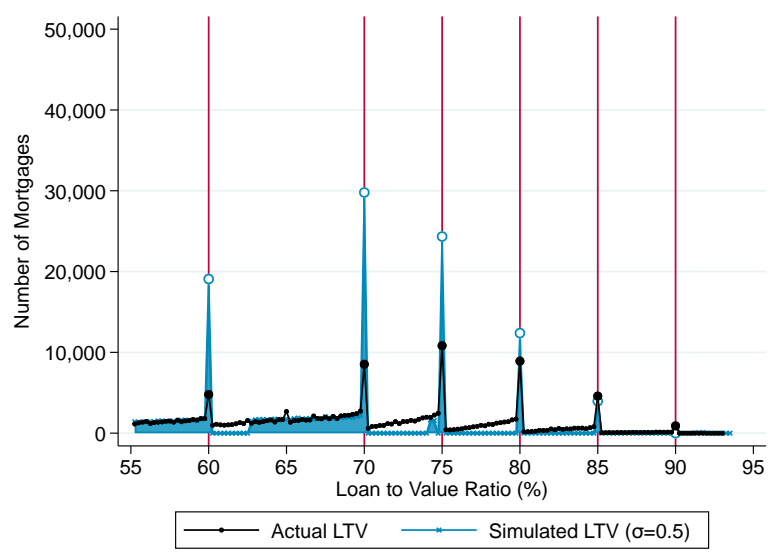

Panel D: $\sigma=2$

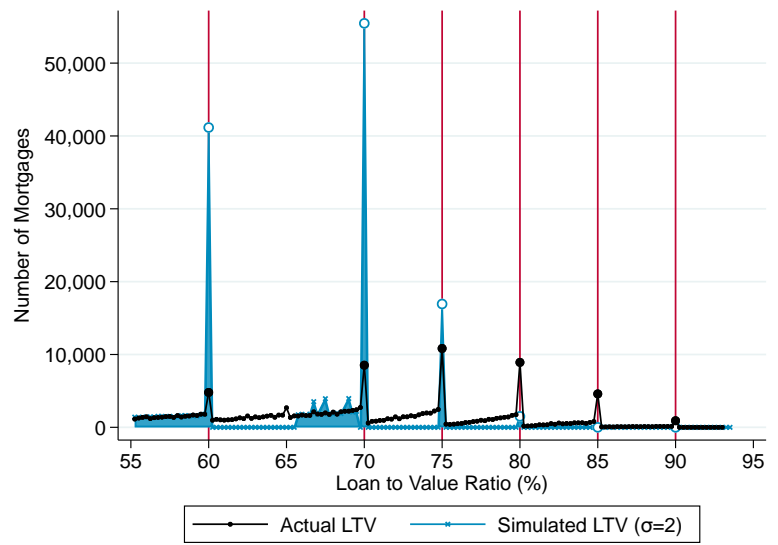

Notes: The figure shows simulations of a model introduced in Section 3 for a range of EIS values. The blue lines show the predicted LTV distribution if households choose leverage optimally according to the model. The black lines show the empirical LTV distribution. The upper left hand corner has $\sigma=0.06$, which is the EIS that minimizes the MSE of the predicted bunching masses. Higher EIS values predict far greater bunching masses than found in the data, with a large share of households jumping more than one notch in the LTV distribution to exploit lower interest charges. The distribution largely hollows out between notches, in contrast to the data. 


\section{Figure 7: Bunching Estimation When Pooling Notches}

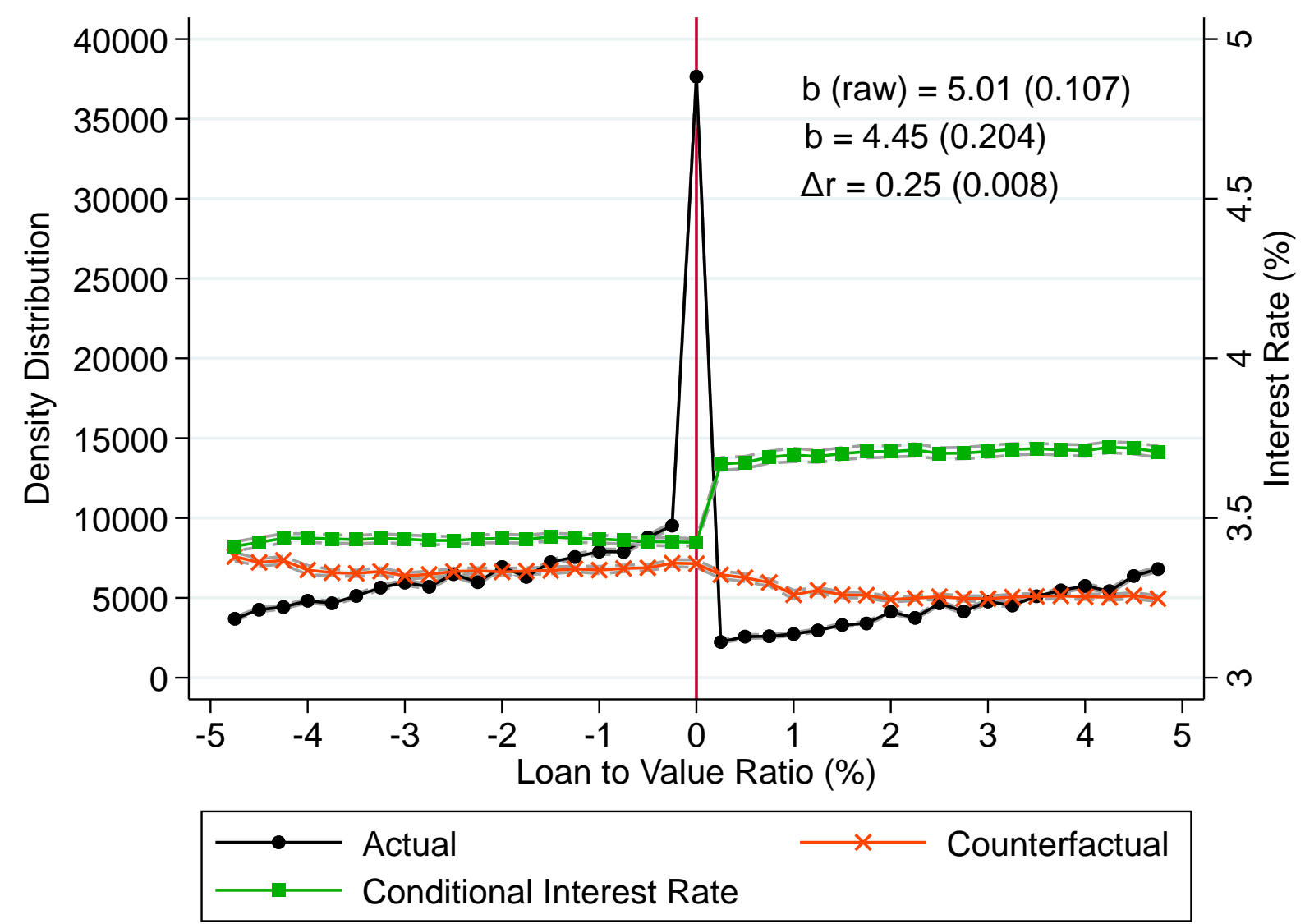

Notes: The figure shows the actual $\left(f(\lambda)\right.$ in black dots) and counterfactual $\left(f_{0}(\lambda)\right.$ in orange crosses) distributions of LTV $(\lambda)$, pooling all notches $(60 \%, 70 \%, 75 \%, 80 \%, 85 \%)$. The green squares show the conditional interest rate in each LTV bin from the regression described in Section 2.3 and the footnote to Figure 3. The counterfactual LTV distribution is obtained using the method outlined in Section 2.4 and the footnote to Figure 4. The figure also shows the jump in the conditional interest rate at the notch $\Delta r$; the (raw) normalized amount of bunching in the actual distribution $b$ (raw), calculated as described in Section 3; and $b$ which is the amount of bunching net of round number bunching. 


\section{FiguRE 8: BUNCHING ESTIMATION AT INDIVIDUAL NotCheS}

\section{Panel A: 70\% LTV Notch}

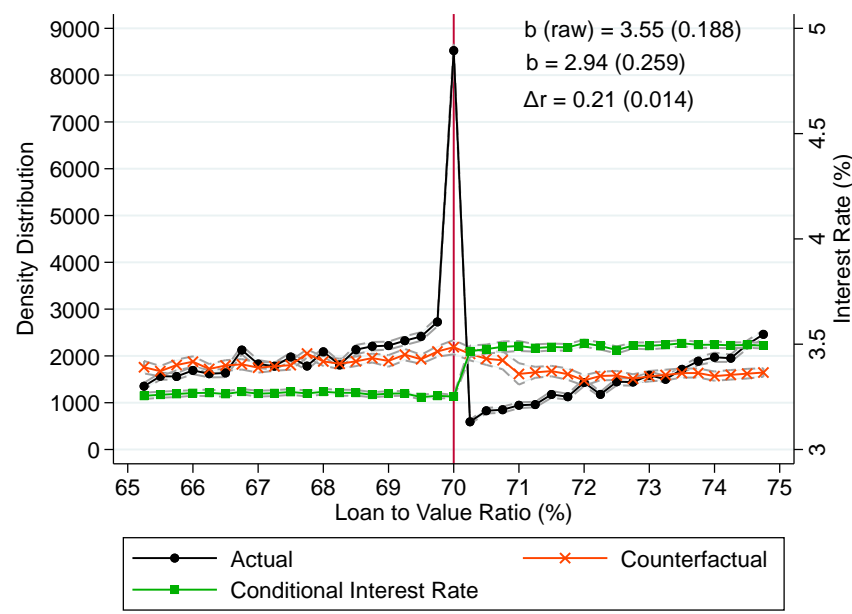

来
Panel B: 75\% LTV Notch

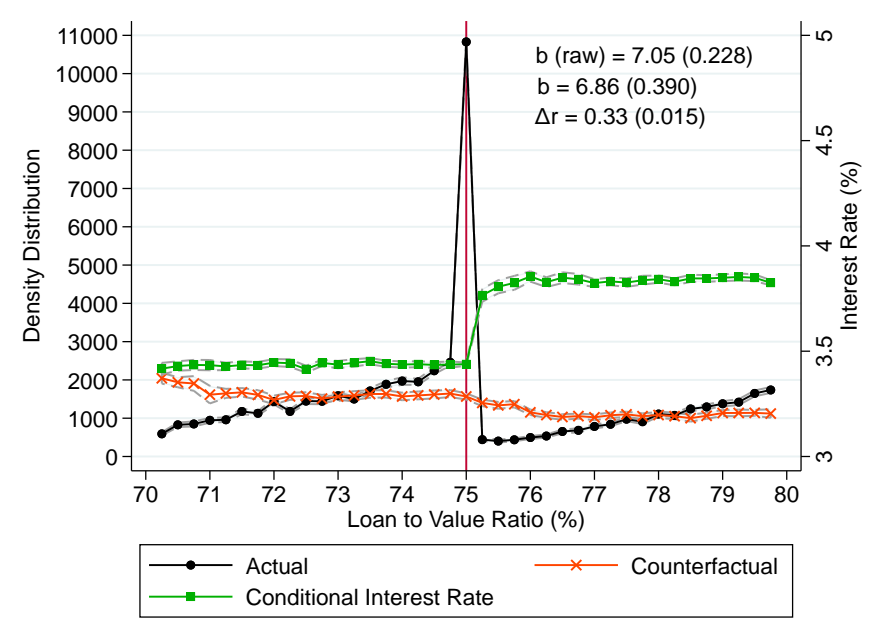

Panel D: 85\% LTV Notch

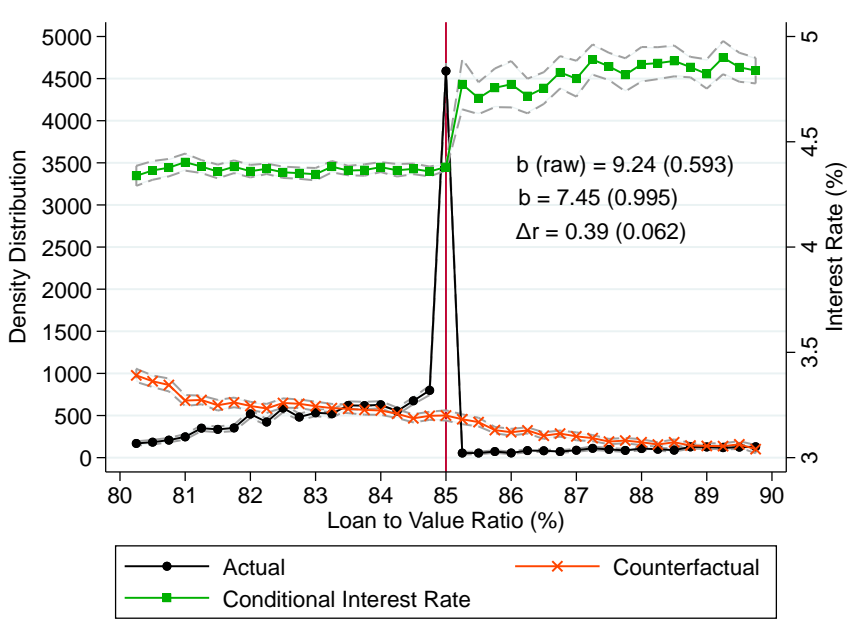

Notes: The figure shows the actual $\left(f(\lambda)\right.$ in black dots) and counterfactual $\left(f_{0}(\lambda)\right.$ in orange crosses) distributions of LTV $(\lambda)$, at the notches at $70 \%$ (Panel A), $75 \%$ (Panel B), 80\% (Panel C) and 85\% (Panel D) LTV. The green squares show the conditional interest rate in each LTV bin from regression described in Section 2.3 and the footnote to Figure 3. The counterfactual LTV distribution is obtained using the method outlined in Section 2.4 and the footnote to Figure 4 . The figure also shows the jump in the conditional interest rate at the notch $\Delta r$; the (raw) normalized amount of bunching in the actual distribution $b($ raw), calculated as described in Section 3 ; and $b$ which is the amount of bunching net of round number bunching. 
Table 1: Descriptive Statistics Across Samples

\begin{tabular}{lccc}
\hline & $(1)$ & $(2)$ & $(3)$ \\
& $\begin{array}{c}\text { Full sample } \\
\text { mean/sd }\end{array}$ & $\begin{array}{c}\text { Remortgagors } \\
\text { mean/sd }\end{array}$ & $\begin{array}{c}\text { Remortgagor panel } \\
\text { mean/sd }\end{array}$ \\
\hline Interest Rate $(\%)$ & 4.12 & 4.26 & 4.06 \\
Loan Size $(\mathcal{E})$ & $(1.29)$ & $(1.38)$ & $(1.23)$ \\
& $142,710.6$ & $138,376.2$ & $145,400.8$ \\
Property Value $(\mathcal{E})$ & $(120,512.8)$ & $(120,725.2)$ & $(116,489.4)$ \\
& $257,004.0$ & $263,076.4$ & $262,304.0$ \\
Loan to Value Ratio $(\%)$ & $(255,284.2)$ & $(270,122.1)$ & $(247,074.1)$ \\
& 59.9 & 56.4 & 58.8 \\
Gross Income (£) & $(22.1)$ & $(21.7)$ & $(19.8)$ \\
Loan to Income Ratios & $57,270.6$ & $57,480.9$ & $57,483.2$ \\
Repayments to Income $(\%)$ & $(84,069.3)$ & $(84,517.4)$ & $(77,513.0)$ \\
& 2.78 & 2.68 & 2.78 \\
Proportion with Joint Income & $(1.85)$ & $(2.03)$ & $(1.60)$ \\
& 21.8 & 22.6 & 21.9 \\
Mortgage Term (years) & $(39.5)$ & $(48.4)$ & $(15.4)$ \\
& 0.54 & 0.55 & 0.55 \\
Proportion of Fixed Rate Mortgages & $(0.50)$ & $(0.50)$ & $(0.50)$ \\
& 20.7 & 19.0 & 20.0 \\
Proportion of Remortgagors & $(7.44)$ & $(6.92)$ & $(6.65)$ \\
Borrower's Age & 0.68 & 0.65 & 0.73 \\
& $(0.47)$ & $(0.48)$ & $(0.45)$ \\
Observations & 0.56 & 0.88 & 0.76 \\
& $(0.50)$ & $(0.32)$ & $(0.42)$ \\
& 40.0 & 41.7 & 40.3 \\
& $(10.0)$ & $(9.57)$ & 647,192 \\
\hline
\end{tabular}

Notes: The table shows summary statistics of the three samples used in our analysis. Column (1) shows our full sample: all usable mortgages in the PSD (house purchases and refis) including (a) observations where we can find information on the product fee in MoneyFacts (b) any refinancer's previous mortgage (which we can use without fee information). Column (2) restricts the sample to refinancers only (all refinance products and any refinancer's previous mortgage). Finally, column (3) shows the sample of refinancers in the panel (refinancers we can link over time and where we can construct a counterfactual LTV ratio). 
TABLE 2: FROM BUNCHING TO THE EIS: SIMPLE MODEL

\begin{tabular}{|c|c|c|c|c|c|c|}
\hline \multirow{2}{*}{ Statistic } & \multicolumn{6}{|c|}{ Notch } \\
\hline & 60 & 70 & 75 & 80 & 85 & Pooled \\
\hline \multicolumn{7}{|c|}{ Panel A: Bunching Evidence } \\
\hline$r(\%)$ & $\begin{array}{c}3.17 \\
(0.01)\end{array}$ & $\begin{array}{c}3.25 \\
(0.00)\end{array}$ & $\begin{array}{c}3.44 \\
(0.00)\end{array}$ & $\begin{array}{c}3.76 \\
(0.00)\end{array}$ & $\begin{array}{c}4.38 \\
(0.01)\end{array}$ & $\begin{array}{c}3.42 \\
(0.01)\end{array}$ \\
\hline$\Delta r(\%)$ & $\begin{array}{c}0.10 \\
(0.01)\end{array}$ & $\begin{array}{c}0.21 \\
(0.01)\end{array}$ & $\begin{array}{c}0.33 \\
(0.02)\end{array}$ & $\begin{array}{c}0.37 \\
(0.02)\end{array}$ & $\begin{array}{c}0.39 \\
(0.06)\end{array}$ & $\begin{array}{c}0.25 \\
(0.01)\end{array}$ \\
\hline$b$ & $\begin{array}{c}0.96 \\
(0.17)\end{array}$ & $\begin{array}{c}2.94 \\
(0.26)\end{array}$ & $\begin{array}{c}6.86 \\
(0.39)\end{array}$ & $\begin{array}{c}6.42 \\
(0.74)\end{array}$ & $\begin{array}{c}7.45 \\
(0.99)\end{array}$ & $\begin{array}{c}4.45 \\
(0.20)\end{array}$ \\
\hline$a$ & $\begin{array}{c}0.58 \\
(0.05)\end{array}$ & $\begin{array}{c}0.21 \\
(0.02)\end{array}$ & $\begin{array}{c}0.30 \\
(0.03)\end{array}$ & $\begin{array}{c}0.15 \\
(0.02)\end{array}$ & $\begin{array}{c}0.08 \\
(0.03)\end{array}$ & $\begin{array}{c}0.29 \\
(0.01)\end{array}$ \\
\hline$b_{A d j}$ & $\begin{array}{c}2.31 \\
(0.49)\end{array}$ & $\begin{array}{c}3.73 \\
(0.35)\end{array}$ & $\begin{array}{c}9.87 \\
(0.60)\end{array}$ & $\begin{array}{c}7.59 \\
(0.89)\end{array}$ & $\begin{array}{c}8.11 \\
(1.16)\end{array}$ & $\begin{array}{c}6.30 \\
(0.30)\end{array}$ \\
\hline$\Delta \lambda_{A d j}$ & $\begin{array}{c}0.67 \\
(0.14) \\
\end{array}$ & $\begin{array}{c}1.06 \\
(0.09) \\
\end{array}$ & $\begin{array}{c}3.32 \\
(0.18) \\
\end{array}$ & $\begin{array}{c}2.68 \\
(0.32) \\
\end{array}$ & $\begin{array}{c}3.71 \\
(0.70)\end{array}$ & $\begin{array}{c}1.93 \\
(0.09)\end{array}$ \\
\hline \multicolumn{7}{|c|}{ Panel B: Elasticities } \\
\hline EIS $\sigma$ & $\begin{array}{c}0.03 \\
(0.01)\end{array}$ & $\begin{array}{c}0.03 \\
(0.00)\end{array}$ & $\begin{array}{c}0.17 \\
(0.02)\end{array}$ & $\begin{array}{c}0.08 \\
(0.02)\end{array}$ & $\begin{array}{c}0.13 \\
(0.05)\end{array}$ & $\begin{array}{c}0.07 \\
(0.01)\end{array}$ \\
\hline Reduced-form $\varepsilon$ & $\begin{array}{c}0.53 \\
(0.01)\end{array}$ & $\begin{array}{c}0.53 \\
(0.00)\end{array}$ & $\begin{array}{c}0.60 \\
(0.01)\end{array}$ & $\begin{array}{c}0.56 \\
(0.01)\end{array}$ & $\begin{array}{c}0.58 \\
(0.02)\end{array}$ & $\begin{array}{c}0.55 \\
(0.00)\end{array}$ \\
\hline
\end{tabular}

Notes: The table shows our reduced-form estimates using bunching at the various LTV notches separately, and pooling the notches from $60 \%$ to $85 \%$. $r$ is the conditional nominal interest rate below the notch, $\Delta r$ is the interest rate jump at the notch, estimated as described in Section 2.3, $b_{A d j}$ is our normalized bunching estimate, net of round number bunching and adjusted for optimization frictions, and $\Delta \lambda_{A d j}$ is our estimate of the leverage response, estimated as described in Section 3. The EIS $\sigma$ is estimated using a simple 2-period model described in Section 3: the solution to the indifference equation (8). The reduced form elasticity is obtained using (10), derived in Section 3. The standard errors, shown in parentheses, are obtained by bootstrapping the estimation routine, stratifying by notch, 100 times. 
TABle 3: BoUnding OPTIMIZATION FRICTIONS AND THE EIS

\begin{tabular}{cccccc}
\hline & $\mathbf{7 0}$ & $\mathbf{7 5}$ & $\mathbf{8 0}$ & $\mathbf{8 5}$ & Pooled \\
\hline \multicolumn{4}{c}{ Panel A: Adjustment Factor $a$} \\
\hline \multirow{2}{*}{ (1) Notched Banks Only } & 0.11 & 0.15 & 0.15 & 0.03 & 0.12 \\
& $(0.02)$ & $(0.02)$ & $(0.03)$ & $(0.01)$ & $(0.01)$ \\
(2) Dominated Region & 0.21 & 0.30 & 0.15 & 0.08 & 0.22 \\
& $(0.02)$ & $(0.03)$ & $(0.02)$ & $(0.03)$ & $(0.01)$ \\
(3) Entire Hole & 0.67 & 0.60 & 0.57 & 0.40 & 0.61 \\
& $(0.05)$ & $(0.02)$ & $(0.04)$ & $(0.09)$ & $(0.02)$ \\
\hline \multirow{2}{*}{ Panel B: Elasticity of Intertemporal Substitution $\sigma$} & \\
\hline \multirow{2}{*}{ (4) Unadjusted } & 0.02 & 0.08 & 0.06 & 0.11 & 0.05 \\
& $(0.00)$ & $(0.01)$ & $(0.01)$ & $(0.04)$ & $(0.01)$ \\
(5) Notched Banks Only & 0.02 & 0.11 & 0.08 & 0.11 & 0.07 \\
& $(0.00)$ & $(0.01)$ & $(0.02)$ & $(0.04)$ & $(0.01)$ \\
(6) Dominated Region & 0.03 & 0.17 & 0.08 & 0.13 & 0.09 \\
& $(0.00)$ & $(0.02)$ & $(0.02)$ & $(0.05)$ & $(0.01)$ \\
(7) Entire Hole & 0.16 & 0.50 & 0.31 & 0.30 & 0.30 \\
& $(0.05)$ & $(0.07)$ & $(0.08)$ & $(8.53)$ & $(0.03)$ \\
\hline
\end{tabular}

Notes: The table shows how the estimated EIS is affected by assumptions on optimization frictions. The top panel shows the friction-adjustment factor $a$ estimated in three cases. Row (1) shows the estimate when restricting the sample to banks that have a non-zero interest rate notch. Row (2) shows our preferred estimate using the observed mass in the dominated region as given by equation (11). Row (3) calculates $a$ for the extreme assumption that all households in the hole above the notch are non-optimizers. The bottom panel shows the estimated EIS. Row (4) estimates the EIS without the friction adjustment; row (5) for notched banks only using the frictions adjustment from row (2); row (6) for the adjustment using the dominated region from row (3); and row (7) for the case that all households in the "hole" above the notch are nonoptimizers as in row (4). 
TABle 4: HeTEROgeneity IN THE EIS

\begin{tabular}{lcccc}
\hline \multirow{2}{*}{ Covariate } & \multicolumn{4}{c}{ Quartile } \\
& $\mathbf{1}$ & $\mathbf{2}$ & $\mathbf{3}$ & $\mathbf{4}$ \\
\hline \multirow{2}{*}{ Age } & 0.05 & 0.09 & 0.10 & 0.15 \\
& $(0.01)$ & $(0.02)$ & $(0.02)$ & $(0.08)$ \\
Household Income & 0.09 & 0.08 & 0.07 & 0.05 \\
& $(0.02)$ & $(0.01)$ & $(0.01)$ & $(0.01)$ \\
Loan to Income & 0.02 & 0.05 & 0.08 & 0.07 \\
\multirow{2}{*}{ Income Growth } & $(0.01)$ & $(0.01)$ & $(0.01)$ & $(0.02)$ \\
& 0.05 & 0.06 & 0.07 & 0.07 \\
House Price Growth Rate & $(0.01)$ & $(0.02)$ & $(0.01)$ & $(0.02)$ \\
& 0.06 & 0.05 & 0.04 & 0.13 \\
Interest Rate Change (Passive) & $(0.02)$ & $(0.01)$ & $(0.01)$ & $(0.03)$ \\
& 0.02 & 0.06 & 0.11 & 0.11 \\
& $(0.01)$ & $(0.02)$ & $(0.03)$ & $(0.03)$ \\
\hline
\end{tabular}

Notes: The table shows the heterogeneity in our estimated EIS $\sigma$ (using the pooled average notch) by age, income, loan to income (LTI), income growth, house price growth, interest rate change since the previous mortgage (assuming passive borrower behavior). For each covariate, we partition the refinancer panel into 4 quartiles and separately estimate $\sigma$ in each quartile. The standard errors, shown in parentheses, are obtained by bootstrapping the estimation routine, stratifying by notch, 100 times. 
TABle 5: From Bunching to the EIS: Full Structural Model

\begin{tabular}{lcccccc}
\hline \multirow{2}{*}{ Statistic } & $\mathbf{6 0}$ & $\mathbf{7 0}$ & $\mathbf{7 5}$ & $\mathbf{8 0}$ & $\mathbf{8 5}$ & Average \\
\hline \multirow{2}{*}{$b$} & 0.96 & 2.94 & 6.86 & 6.42 & 7.45 & 4.11 \\
& $(0.17)$ & $(0.26)$ & $(0.39)$ & $(0.74)$ & $(0.99)$ & $(0.19)$ \\
$a$ & 0.58 & 0.21 & 0.30 & 0.15 & 0.08 & 0.31 \\
& $(0.05)$ & $(0.02)$ & $(0.03)$ & $(0.02)$ & $(0.03)$ & $(0.01)$ \\
$b_{\text {Adj }}$ & 2.31 & 3.73 & 9.87 & 7.59 & 8.11 & 5.57 \\
& $(0.49)$ & $(0.35)$ & $(0.60)$ & $(0.89)$ & $(1.16)$ & $(0.26)$ \\
$\Delta \lambda_{A d j}$ & 0.67 & 1.06 & 3.32 & 2.68 & 3.71 & 1.88 \\
& $(0.14)$ & $(0.09)$ & $(0.18)$ & $(0.32)$ & $(0.70)$ & $(0.09)$ \\
\multirow{2}{*}{ EIS $\sigma$} & 0.05 & 0.04 & 0.11 & 0.11 & 0.28 & 0.08 \\
& $(0.01)$ & $(0.01)$ & $(0.01)$ & $(0.02)$ & $(0.15)$ & $(0.01)$ \\
\hline
\end{tabular}

Notes: The table shows the results of our structural estimation as described in Section $5 . b$ is our normalized bunching estimate as described in Section 3 and the footnote to Figure 8. $a$ is the adjustment factor for optimization frictions (the number of individuals observed in the dominated region divided by the number of individuals in the same region in the counterfactual distribution), and $b_{A d j}=b /(1-a)$ is our bunching estimate, adjusted for optimization frictions. $\Delta \lambda$ is the leverage response corresponding to $b_{A d j} . \sigma$ is the Elasticity of Intertemporal Substitution (EIS) that solves the full model described in Section 5. The standard errors, shown in parentheses, are obtained by bootstrapping the estimation routine, stratifying by notch, 100 times. 
TABLE 6: Robustness of EIS Estimates

\begin{tabular}{|c|c|c|c|c|c|}
\hline \multirow[b]{2}{*}{ (1) } & \multirow{2}{*}{$\begin{array}{l}\text { Discount } \\
\text { Factor } \delta\end{array}$} & 0.7 & 0.9 & 0.96 & 0.99 \\
\hline & & $\begin{array}{c}0.13 \\
(0.015)\end{array}$ & $\begin{array}{c}0.12 \\
(0.015)\end{array}$ & $\begin{array}{c}0.08 \\
(0.011)\end{array}$ & $\begin{array}{c}0.12 \\
(0.013) \\
\end{array}$ \\
\hline \multirow[b]{2}{*}{ (2) } & \multirow{2}{*}{$\begin{array}{l}\text { Present } \\
\text { Bias } \\
\text { Factor } \beta\end{array}$} & 0.3 & 0.5 & 0.7 & 1 \\
\hline & & $\begin{array}{c}0.17 \\
(0.026)\end{array}$ & $\begin{array}{c}0.14 \\
(0.019)\end{array}$ & $\begin{array}{c}0.11 \\
(0.015)\end{array}$ & $\begin{array}{c}0.08 \\
(0.011)\end{array}$ \\
\hline \multirow[b]{2}{*}{ (3) } & \multirow{2}{*}{$\begin{array}{l}\text { Risk } \\
\text { Aversion } \gamma\end{array}$} & 0 & 1 & 2 & CRRA \\
\hline & & $\begin{array}{c}0.11 \\
(0.011)\end{array}$ & $\begin{array}{c}0.12 \\
(0.012)\end{array}$ & $\begin{array}{c}0.08 \\
(0.011)\end{array}$ & $\begin{array}{c}0.15 \\
(0.013)\end{array}$ \\
\hline \multirow[b]{2}{*}{ (4) } & \multirow{2}{*}{$\begin{array}{l}\text { Future } \\
\text { Interest } \\
\text { Rates }\end{array}$} & $+0 \mathrm{pp}$ & $+1 \mathrm{pp}$ & $+2 \mathrm{pp}$ & $+3 p p$ \\
\hline & & $\begin{array}{c}0.08 \\
(0.011) \\
\end{array}$ & $\begin{array}{c}0.11 \\
(0.014)\end{array}$ & $\begin{array}{c}0.12 \\
(0.013) \\
\end{array}$ & $\begin{array}{c}0.12 \\
(0.013) \\
\end{array}$ \\
\hline \multirow[b]{2}{*}{ (5) } & \multirow{2}{*}{$\begin{array}{l}\text { House } \\
\text { Price } \\
\text { Trend }\end{array}$} & $-0.6 \%$ & 0 & $0.6 \%$ & $6 \%$ \\
\hline & & $\begin{array}{c}0.10 \\
(0.014)\end{array}$ & $\begin{array}{c}0.10 \\
(0.014) \\
\end{array}$ & $\begin{array}{c}0.08 \\
(0.011)\end{array}$ & $\begin{array}{c}0.10 \\
(0.014)\end{array}$ \\
\hline \multirow[b]{2}{*}{ (6) } & \multirow{2}{*}{$\begin{array}{l}\text { House } \\
\text { Price } \\
\text { Variance }\end{array}$} & 0 & 0.004 & 0.006 & 0.008 \\
\hline & & $\begin{array}{c}0.08 \\
(0.009)\end{array}$ & $\begin{array}{c}0.10 \\
(0.011)\end{array}$ & $\begin{array}{c}0.08 \\
(0.011)\end{array}$ & $\begin{array}{c}0.16 \\
(0.012)\end{array}$ \\
\hline \multirow{2}{*}{ (7) } & \multirow{2}{*}{$\begin{array}{l}\text { Lifecycle } \\
\text { Income } \\
\text { Profile }\end{array}$} & $\begin{array}{c}£ 44 \mathrm{~K} \\
0 \%\end{array}$ & $\begin{array}{l}£ 46 \mathrm{~K} \\
0.7 \%\end{array}$ & $\begin{array}{l}£ 56 \mathrm{~K} \\
2.7 \%\end{array}$ & $\begin{array}{l}£ 80 \mathrm{~K} \\
6.5 \%\end{array}$ \\
\hline & & $\begin{array}{c}0.12 \\
(0.016)\end{array}$ & $\begin{array}{c}0.08 \\
(0.011)\end{array}$ & $\begin{array}{c}0.09 \\
(0.008)\end{array}$ & $\begin{array}{c}0.08 \\
(0.016)\end{array}$ \\
\hline \multirow[b]{2}{*}{ (8) } & \multirow{2}{*}{$\begin{array}{l}\text { Unemployment } \\
\text { Probability }\end{array}$} & $3 \%$ & $5 \%$ & $7 \%$ & $10 \%$ \\
\hline & & $\begin{array}{c}0.09 \\
(0.014)\end{array}$ & $\begin{array}{c}0.08 \\
(0.011)\end{array}$ & $\begin{array}{c}0.11 \\
(0.013)\end{array}$ & $\begin{array}{c}0.12 \\
(0.015)\end{array}$ \\
\hline \multirow{2}{*}{ (9) } & \multirow{2}{*}{$\begin{array}{l}\text { Replacement } \\
\text { Rate }\end{array}$} & $60 \%$ & $80 \%$ & $100 \%$ & \\
\hline & & $\begin{array}{c}0.08 \\
(0.011)\end{array}$ & $\begin{array}{c}0.13 \\
(0.013)\end{array}$ & $\begin{array}{c}0.12 \\
(0.016)\end{array}$ & \\
\hline
\end{tabular}

Notes: The table shows the robustness of our estimates of the elasticity of intertemporal substitution $\sigma$ to a number of the assumptions of our structural model. Panel (1) varies the discount factor $\delta$. Panel (2) relaxes our assumption that households discount the future with traditional geometric discounting, and allows for quasi-hyperbolic $\beta-\delta$ discounting with present bias parameters $\beta$ from 0.3 to 1 (geometric discounting). Panel (3) varies the coefficient of relative risk aversion $\gamma$. Panel (4) varies (deterministic) future interest rates by shifting the entire yield curve up by $1 \mathrm{pp}$ to $3 p p$. Panel (5) varies real house price growth ranging from house price declines to house price increases an order of magnitude larger. Panel (6) varies the variance of house price growth in household expectations. Panel (7) varies the deterministic lifecycle component of income expectations. In all cases, the lifecycle component is quadratic. The "Peak" parameter gives peak income and the "Slope" parameter gives expected income growth at the time of refinancing. Panels (8) and (9) vary assumptions on income uncertainty, with panel (8) varying the probability of unemployment and panel (9) the unemployment replacement rate. 